\title{
Behavioral risky hesitant fuzzy linguistic multiple attribute decision making with priority degree method
}

\author{
Wangwang Yu Xinwang Liu * \\ School of Economics and Management, Southeast University, Nanjing, 210096, Jiangsu, China.
}

\begin{abstract}
In this paper, we propose a behavioral risky hesitant fuzzy linguistic multiple attribute decision making with priority degree method. First, we define a new ranking method for hesitant fuzzy linguistic term sets to compare the hesitant fuzzy linguistic evaluation information and the expectation. Second, we give a relative distance for the hesitant fuzzy linguistic term set to get the distance between the hesitant fuzzy linguistic evaluation information and expectation. Third, we use the prospect theory, the new defined ranking method and the new defined distance formula to get interval individual prospect value. Forth, we apply the average operator to get interval comprehensive prospect value. Fifth, we define a priority degree method of interval number to rank interval comprehension prospect value. Based on the above steps, we give the solution of risky hesitant fuzzy linguistic multiple attribute decision making problem. Further, we use the example to illustrate the feasibility and rationality of this behavior method and the comparative analysis between the existing decision making method for the hesitant fuzzy linguistic term.
\end{abstract}

Keywords: Hesitant fuzzy linguistic term set, Prospect theory, Priority degree method, Multiple attribute decision making.

\footnotetext{
${ }^{*}$ Corresponding author. E-mail address: xwliu@seu.edu.cn,17855379910@163.com, Telephone number(s):
} 


\section{Introduction}

When decision makers doubt between different linguistic terms and require more complex linguistic term to express their assessments, fuzzy linguistic approaches ${ }^{1-5}$ are invalid. Rodríguez et al. ${ }^{6}$ introduced the hesitant fuzzy linguistic term set based on the hesitant fuzzy set ${ }^{7,8}$ and extended the context-free grammars of linguistic variables, which provides a different and great flexible form to represent the assessments of decision makers.

The ranking method for hesitant fuzzy linguistic term sets is an very important research direction in the field of decision making ${ }^{6,9-13}$. Rodríguez et al. ${ }^{6}$ proposed a comparison relation between two hesitant fuzzy linguistic term sets by the fuzzy envelope of the hesitant fuzzy linguistic element. Lee and Chen ${ }^{10}$ defined the likelihood-based comparison relation between two hesitant fuzzy linguistic term sets by the concept of the 1-cut of a hesitant fuzzy linguistic element. Wei et al. 11 introduced a comparison method for hesitant fuzzy linguistic term sets based on the probability theory. Meanwhile, the ranking method for hesitant fuzzy linguistic term sets has used in the multiple attribute decision-making problems ${ }^{9-13}$.

The multi-criteria decision making problems ${ }^{14-23}$ for hesitant fuzzy linguistic term sets are also very popular in the field of decision making. Sellak et al. ${ }^{14}$ developed knowledge-based outranking approach for multi-criteria decision-making with hesitant fuzzy linguistic term sets. Farhadinia ${ }^{16}$ introduced a multiple criteria decision-making methods with completely unknown weights in hesitant fuzzy linguistic term setting. Wan et al. ${ }^{21}$ given a hesitant fuzzy mathematical programming method for hybrid multi-criteria group decision making with hesitant fuzzy truth degrees. Liang et al. ${ }^{22}$ defined two extended projection-based preference ranking organization methods for multi-criteria decision making with hesitant fuzzy linguistic term sets.

When many researcheres try to consider the influence of people's psychological state in the process of multi-criteria decision making problems, they find that the prospect theory can describe and predict people's psychological state in the processing of risk decision making. Further, the prospect theory ${ }^{24,25}$ is used for the multi-criteria decision making problem ${ }^{26-44}$. Liu et al. ${ }^{26}$ gave a multi-attribute decision making method based on prospect theory with interval probability ${ }^{44-50}$ and the uncertain linguistic evaluation information, Krohling and Souza ${ }^{27}$ proposed a hybrid approach 
combining prospect theory and fuzzy numbers to handle risk and uncertainty in the multi-criteria decision making problems. Xu et al. ${ }^{33}$ introduced the prospect decision-making method and used the hesitant fuzzy linguistic information to express their evaluation information of the decision makers.

However, the existing decision making method ${ }^{26-44}$ with the prospect theory included two problems: (1) The complexity of decision making environment. That is, the existing decision making method ${ }^{26-44}$ do not consider that the decision maker may present the different evaluation information under the different psychological states. (2) The complexity of evaluation information. That is, the existing decision making method ${ }^{26-44}$ do not consider the hesitant fuzzy linguistic evaluation information term and interval probability ${ }^{44-50}$. Here, we will propose a behavioral risky hesitant fuzzy linguistic multiple attribute decision making with priority degree method. The main differences from the works of existing multi-attribute decision making method for hesitant fuzzy linguistic term sets are included as follows:

- The complexity of decision making information. The existing multi-attribute decision making method with prospect theory ${ }^{26-44}$ only consider hesitant fuzzy linguistic evaluation information, uncertain linguistic evaluation information, or interval probability. However, our behavior method both consider the hesitant fuzzy linguistic evaluation information and interval probability.

- The complexity of decision making environment. Our behavior risky hesitant fuzzy linguistic multiple attribute decision making method consider that the decision maker may present the different evaluation information under the different psychological states. However, the existing multi-attribute decision making method ${ }^{26-44}$ do not consider this problem.

- The new ranking method for hesitant fuzzy linguistic evaluation information and expectation. Our defined ranking method for hesitant fuzzy linguistic term sets is more rational and easy understand than the existing ranking method for hesitant fuzzy linguistic term set.

- The transformation of expression way of evaluation information. Here, we use the our defined ranking method, our defined distance formula and prospect theory to transform the hesitant fuzzy linguistic term set into the crisp value for decreasing the complexity of compute. 
- The ranking method for the interval comprehensive prospect value. Our defined priority degree for interval number is more rational than the existing ranking method for the interval number 47,48

The contents of this paper are organized as follows: In section 2, we introduce some basic definition. In section 3, we will give the description of problems. In section 4, we will apply the prospect theory to aggregate the hesitant fuzzy linguistic evaluation information and interval probability. In section 5, we will apply the priority degree method of interval number to rank interval comprehensive prospect value. In section 6, we will give the solution of risky hesitant fuzzy linguistic multiple attribute decision making problem. In section 7 , we will use the example to show the detailed steps of the behavior method and comparative analysis between the existing decision making method for the hesitant fuzzy linguistic term sets. In section 8 , we will give the conclusion and future prospects.

\section{Preliminaries}

\subsection{Hesitant fuzzy linguistic term set and interval number}

In this section, we introduce the concepts of the hesitant fuzzy linguistic term set ${ }^{6}$ and the expression way of comparison relation between two hesitant fuzzy linguistic term sets ${ }^{9-11}$, the basic operation and concept of interval number ${ }^{44-50}$ and the possibility degree formula for interval numbers 47,48

Definition 1. ${ }^{6}$ Let $S$ be a linguistic term set, $S=\left\{s_{0}, \ldots, s_{\tau}\right\}$; a hesitant fuzzy linguistic term set, $H_{S}$, is an ordered finite subset of the consecutive linguistic term of $S$.

Definition 2. ${ }^{6,10,11}$ Let $S=\left\{s_{0}, \ldots, s_{\tau}\right\}$ be a linguistic term set, and $H_{S}^{1}$ and $H_{S}^{2}$ be two arbitrary hesitant fuzzy linguistic term sets on $S$. The expression way of comparison relation between two hesitant fuzzy linguistic term sets are expressed as

Rodíguez et al. ${ }^{6}$ introduced the following formula

$$
p_{R}\left(H_{S}^{1} \geqslant H_{S}^{2}\right)=\frac{\max \left(0, I\left(H_{S}^{1+}\right)-I\left(H_{S}^{2-}\right)\right)-\max \left(0, I\left(H_{S}^{1-}\right)-I\left(H_{S}^{2+}\right)\right)}{\left(I\left(H_{S}^{1+}\right)-I\left(H_{S}^{1-}\right)\right)+\left(I\left(H_{S}^{2+}\right)-I\left(H_{S}^{2-}\right)\right)}
$$


Lee and Chen ${ }^{10}$ proposed the following formula

$$
p_{R}\left(H_{S}^{1} \geqslant H_{S}^{2}\right)=\max \left\{1-\max \left(\frac{I\left(H_{S}^{2+}\right)-I\left(H_{S}^{1-}\right)}{\left(I\left(H_{S}^{1+}\right)-I\left(H_{S}^{1-}\right)\right)+\left(I\left(H_{S}^{2+}\right)-I\left(H_{S}^{2-}\right)\right)}, 0\right)\right\}
$$

Wei et al. ${ }^{11}$ gave the following formula

$$
\begin{aligned}
& p_{w}\left(H_{S}^{1} \geqslant H_{S}^{2}\right)= \\
& \begin{cases}0 & H_{S}^{1+}<H_{S}^{2-} \\
\frac{0.5\left(I\left(H_{S}^{1+}\right)-I\left(H_{S}^{2-}\right)+1\right)}{I\left(H_{S}^{2+}\right)-I\left(H_{S}^{1-}\right)+1} & H_{S}^{1-} \leqslant H_{S}^{2-} \leqslant H_{S}^{1+} \leqslant H_{S}^{2+} \\
\frac{I\left(H_{S}^{1-}\right)-I\left(H_{S}^{2-}\right)+0.5\left(I\left(H_{S}^{1+}\right)-I\left(H_{S}^{1-}\right)+1\right)}{I\left(H_{S}^{2+}\right)-I\left(H_{S}^{2-}\right)+1} & H_{S}^{2-}<H_{S}^{1-} \leqslant H_{S}^{1+}<H_{S}^{2+} \\
\frac{I\left(H_{S}^{1+}\right)-I\left(H_{S}^{2+}\right)+0.5\left(I\left(H_{S}^{2+}\right)-I\left(H_{S}^{2-}\right)+1\right)}{I\left(H_{S}^{2+}\right)-I\left(H_{S}^{1-}\right)+1} & H_{S}^{1-}<H_{S}^{2-} \leqslant H_{S}^{2+}<H_{S}^{1+} \\
\frac{I\left(H_{S}^{1+}\right)-I\left(H_{S}^{2+}\right)+0.5\left(I\left(H_{S}^{2+}\right)-I\left(H_{S}^{1-}\right)+1\right)}{I\left(H_{S}^{2+}\right)-I\left(H_{S}^{1-}\right)+1}+\frac{I\left(H_{S}^{1-}\right)-I\left(H_{S}^{2-}\right)}{I\left(H_{S}^{1+}\right)-I\left(H_{S}^{2-}\right)} & H_{S}^{2-}<H_{S}^{1-} \leqslant H_{S}^{2+}<H_{S}^{1+} \\
1 & H_{S}^{2+}<H_{S}^{1-}\end{cases}
\end{aligned}
$$

where $I\left(H_{S}^{1+}\right)$ denotes the subscript of the upper limit of linguistic term in the hesitant fuzzy linguistic term set $H_{S}^{1} ; I\left(H_{S}^{2+}\right)$ denotes the subscript of the upper limit of linguistic term in the hesitant fuzzy linguistic term set $H_{S}^{2} ; I\left(H_{S}^{1-}\right)$ denotes the subscript of the lower limit of linguistic term in the hesitant fuzzy linguistic term set $H_{S}^{1} ; I\left(H_{S}^{2-}\right)$ denotes the subscript of the lower limit of linguistic term in the hesitant fuzzy linguistic term set $H_{S}^{2}$.

\subsection{The interval number}

Definition 3. ${ }^{45,46}$ Let $\bar{a}_{1}=\left[a_{1}^{-}, a_{1}^{+}\right]=\left\{x \mid a_{1}^{-} \leqslant x \leqslant a_{1}^{+}, x \subseteq R\right\}$, where $a_{1}^{-}$and $a_{1}^{+}$are the left and right limits of the interval $\bar{a}_{1}$ on a fixed set $R$, respectively, if $a_{1}^{-}=a_{1}^{+}=\bar{a}_{1}$, then $\bar{a}_{1}$ is a real number.

Definition 4. ${ }^{44,46,47}$ Let $\bar{a}_{1}=\left[a_{1}^{-}, a_{1}^{+}\right]$and $\bar{a}_{2}=\left[a_{2}^{-}, a_{2}^{+}\right]$be two interval numbers. Then

$$
\begin{aligned}
& \bar{a}_{1} \oplus \bar{a}_{2}=\left[a_{1}^{-}+a_{2}^{-}, a_{1}^{+}+a_{2}^{+}\right] ; \\
& \bar{a}_{1} \ominus \bar{a}_{2}=\left[a_{1}^{-}-a_{2}^{+}, a_{1}^{+}-a_{2}^{-}\right] ; \\
& \lambda \cdot \bar{a}_{1}=\left[\lambda a_{1}^{-}, \lambda a_{1}^{+}\right](\lambda \geqslant 0) ; \\
& \lambda \cdot \bar{a}_{1}=\left[\lambda a_{1}^{+}, \lambda a_{1}^{-}\right](\lambda<0) .
\end{aligned}
$$


Definition 5. ${ }^{47,48}$ Let $\bar{a}_{1}=\left[a_{1}^{-}, a_{1}^{+}\right]$and $\bar{a}_{2}=\left[a_{2}^{-}, a_{2}^{+}\right]$be two interval numbers. The two possibility degree formula are expressed as

$$
D\left(\bar{a}_{1}>\bar{a}_{2}\right)=\frac{\max \left\{0, l\left(\bar{a}_{1}\right)+l\left(\bar{a}_{2}\right)-\max \left(0, \bar{a}_{2}^{+}-\bar{a}_{1}^{-}\right)\right\}}{l\left(\bar{a}_{1}\right)+l\left(\bar{a}_{2}\right)}
$$

and

$$
D\left(\bar{a}_{1}>\bar{a}_{2}\right)=\max \left\{1-\max \left(\frac{\bar{a}_{2}^{+}-\bar{a}_{1}^{-}}{l\left(\bar{a}_{1}\right)+l\left(\bar{a}_{2}\right)}, 0\right), 0\right\}
$$

where $l\left(\bar{a}_{1}\right)=a_{1}^{+}-a_{1}^{-}$and $l\left(\bar{a}_{2}\right)=a_{2}^{+}-a_{2}^{-}$.

\subsection{The Prospect Theory}

The Prospect theory ${ }^{24,25}$ holds that people are more sensitive to loss than to gain. Its value function is $S$-shaped. The area below reference point $\pi_{0}$ is "loss" area, showing preference for risk, and the area above reference point is "gain" area, showing aversion to risk.

The prospect utility value function is

$$
U=v(\triangle x) \times w(P)
$$

where $\triangle x=x-x_{0}$ is the subjective value, $w(P)$ is weight of decision-making.

The subjective value and probability weight are mostly algebraic forms proposed by Kahneman et al. The subjective value function is

$$
v(\triangle x)= \begin{cases}(\triangle x)^{\alpha} & \triangle x \geqslant 0 \\ -\lambda(-\triangle x)^{\beta} & \triangle x<0\end{cases}
$$

where $\alpha$ and $\beta$ denote the risk attitude coefficient of decision maker's "preference" and "avoidance" for risk, respectively, and $\lambda$ expresses the sensitivity coefficients of loss and gain. $0<\alpha, \beta<1$. The greater the parameter, the weaker the sensibility of decision maker to value, and $\lambda>1$ expresses the more disgusted the loss. The probability weight is

$$
w(P)^{+}=\frac{p^{\gamma}}{\left(p^{\gamma}+\left(1-p^{\gamma}\right)\right)^{1 / \gamma}}
$$




$$
w(P)^{-}=\frac{p^{\delta}}{\left(p^{\delta}+\left(1-p^{\delta}\right)\right)^{1 / \delta}}
$$

where $w(P)^{+}$and $w(P)^{-}$denote nonlinear weight functions of gain and loss, $w(0)=0, w(1)=1$; $\gamma$ and $\delta$ denote the risk attitude coefficient of decision-makers when they perceive "gain" and "loss", respectively. Tversky and Kahneman ${ }^{25}$ determined that $\alpha=\beta=0.88, \lambda=2.25, \gamma=0.61$ and $\delta=0.69$, which will be adopted in our case study in section 7 .

\section{The description of problems for risky hesitant fuzzy linguistic multiple attribute decision making}

In this section, we give the two problems for the existing decision making method ${ }^{26-44}$ with the prospect theory: (1) The complexity of decision making environment. That is, the existing decision making method ${ }^{26-44}$ do not consider that the decision maker may present the different evaluation information under the different psychological states. (2) The complexity of evaluation information. That is, the existing decision making method ${ }^{26-44}$ do not consider the hesitant fuzzy linguistic evaluation information term and interval probability. Here, we will give the description of problems for risky hesitant fuzzy linguistic multiple attribute decision making. As follows:

There is a set $A$ of alternatives, $A=\left\{A_{1}, \ldots, A_{n}\right\}$, a set $C$ of criteria, $C=\left\{C_{1}, \ldots, C_{m}\right\}$, and a weighting vector $W, W=\left(w_{1}, \ldots, w_{m}\right)$, where $w_{j}$ represents the weight of criteria $C_{j}(1 \leqslant j \leqslant m)$, and $w_{j} \geqslant 0, \sum_{j=1}^{m} w_{j}=1 ; T=\left\{T_{1}, \ldots, T_{f}\right\}$ represents a collection of natural states, where $T_{t}(1 \leqslant$ $t \leqslant f)$ represents the $t$ th status, $\bar{P}_{t}=\left[P_{t}^{-}, P_{t}^{+}\right](1 \leqslant t \leqslant f)$ represents the probability of occurrence of $T_{t}(1 \leqslant t \leqslant f)$, and $P_{t}$ is a interval number; $X=\left(x_{i j}^{t}\right)_{n \times m \times f}$ represents decision matrix, where $x_{i j}^{t}(1 \leqslant i \leqslant n, 1 \leqslant j \leqslant m, 1 \leqslant t \leqslant f)$ represents the result of the alternative $A_{i}(1 \leqslant i \leqslant n)$ for attribute $C_{j}(1 \leqslant j \leqslant m)$ under the state $T_{t}(1 \leqslant t \leqslant f), x_{i j}^{t}(1 \leqslant i \leqslant n, 1 \leqslant j \leqslant m, 1 \leqslant t \leqslant f)$ is a hesitant fuzzy linguistic term set. $R=\left(r_{1}, \ldots, r_{n}\right)$ represents the expected vector of criteria based on existing information and future expectations, where $r_{j}=\left(r_{j}^{1}, \ldots, r_{j}^{f}\right)$ represents the expectations of decision makers for criteria $C_{j}(1 \leqslant j \leqslant m)$, and $r_{j}^{t}(1 \leqslant j \leqslant m, 1 \leqslant t \leqslant f)$ denotes the expectation of decision makers for criteria $C_{j}(1 \leqslant j \leqslant m)$ under state $T_{t}(1 \leqslant t \leqslant f)$. According to the actual situation, we consider $r_{j}^{t}(1 \leqslant j \leqslant m, 1 \leqslant t \leqslant f)$ as the hesitant fuzzy linguistic term sets. Hesitant 
fuzzy linguistic decision matrix $X$ and hesitant fuzzy linguistic expected vector $R$ can be represented as form of Table 1 .

Table 1: Hesitant linguistic fuzzy decision making matrix, hesitant fuzzy linguistic expected vector

\begin{tabular}{c|ccc|ccc|c|ccc}
\hline Criteria & \multicolumn{3}{|c|}{$C_{1}$} & \multicolumn{3}{c|}{$C_{2}$} & $\ldots$ & \multicolumn{3}{c}{$C_{m}$} \\
\hline State & $T_{1}$ & $\ldots$ & $T_{f}$ & $T_{1}$ & $\ldots$ & $T_{f}$ & $\ldots$ & $T_{1}$ & $\ldots$ & $T_{f}$ \\
\hline Probability & $\bar{P}_{1}$ & $\ldots$ & $\bar{P}_{f}$ & $P_{1}$ & $\ldots$ & $\bar{P}_{f}$ & $\ldots$ & $\bar{P}_{1}$ & $\ldots$ & $\bar{P}_{f}$ \\
\hline$A_{1}$ & $x_{11}^{1}$ & $\ldots$ & $x_{11}^{f}$ & $x_{12}^{1}$ & $\ldots$ & $x_{12}^{f}$ & $\ldots$ & $x_{1 m}^{1}$ & $\ldots$ & $x_{1 m}^{f}$ \\
$A_{2}$ & $x_{21}^{1}$ & $\ldots$ & $x_{21}^{f}$ & $x_{22}^{1}$ & $\ldots$ & $x_{22}^{f}$ & $\ldots$ & $x_{2 m}^{1}$ & $\ldots$ & $x_{2 m}^{f}$ \\
$\ldots$ & $\ldots$ & $\ldots$ & $\ldots$ & $\ldots$ & $\ldots$ & $\ldots$ & $\ldots$ & $\ldots$ & $\ldots$ & $\ldots$ \\
$A_{n}$ & $x_{n 1}^{1}$ & $\ldots$ & $x_{n 1}^{f}$ & $x_{n 2}^{1}$ & $\ldots$ & $x_{n 2}^{f}$ & $\ldots$ & $x_{n m}^{1}$ & $\ldots$ & $x_{n m}^{f}$ \\
\hline Expectation & $r_{1}^{1}$ & $\ldots$ & $r_{1}^{f}$ & $r_{2}^{1}$ & $\ldots$ & $r_{2}^{f}$ & $\ldots$ & $r_{m}^{1}$ & $\ldots$ & $r_{m}^{f}$ \\
\hline
\end{tabular}

The problem we want to solve is to get the ranking results of all the alternatives by an effective multiple attribute decision making method based on decision matrix $X$, weighting vector $W$ and expected vector $R$.

Here, we give the solution for risky hesitant fuzzy linguistic multiple attribute decision making problem. As follows:

\section{- The prospect theory is applied to aggregate hesitant fuzzy linguistic evaluation} information and interval probability. First, we use the new defined ranking method of the hesitant fuzzy linguistic term set to compare the hesitant fuzzy linguistic evaluation information and hesitant fuzzy linguistic expectation. Second, we use the new defined distance formula of the hesitant fuzzy linguistic term set and prospect theory to get the value gain and loss. Third, we use the prospect theory to get the interval probability weight of the gain and loss. Then, we use the prospect utility value function to get the interval individual prospect theory value. Finally, we use the average operator to aggregate the interval individual prospect value. Based on the above mentioned steps, we get the interval comprehension prospect value of each alternatives $A_{i}(1 \leqslant i \leqslant n)$.

- The priority degree method of interval number is applied to rank interval comprehensive prospect value. Here, we use the priority degree method of interval number to get the ranking result of interval comprehensive prospect theory value. Further, we get the ranking result of alternatives $A_{i}(1 \leqslant i \leqslant n)$ 
According to the above mentioned solution, we give a behavior method for risky hesitant fuzzy linguistic multiple attribute decision making with priority degree method. The detailed process of theories part are expressed by the section 4 and 5 .

\section{The prospect theory is applied to aggregate hesitant linguistic fuzzy evaluation information and interval probability}

In this section, we will use the prospect theory to aggregate the hesitant fuzzy linguistic evaluation information and interval probability. First, we propose a ranking method of hesitant fuzzy linguistic term sets to compare the hesitant fuzzy linguistic evaluation information and expectation. Second, we introduce a relative distance formula of the hesitant fuzzy linguistic term sets to get the distance between the hesitant fuzzy linguistic evaluation information and expectation. Then, we use the prospect theory, the new defined ranking method and new distance formula to get the interval individual prospect value. Finally, we use the average operator to get the interval comprehensive prospect value. The detailed steps are shown as follows:

\subsection{The ranking method for the hesitant fuzzy linguistic term sets}

In this section, we will propose a ranking method for the hesitant fuzzy linguistic term sets. First, we give a ranking formula for the hesitant fuzzy linguistic term sets and their property. Second, we introduce the relationship between the new ranking formula and existing ranking formula ${ }^{6,10,11}$ for the hesitant fuzzy linguistic term sets. The result is that our ranking formula is more rational than the existing ranking formula for the hesitant fuzzy linguistic term sets. Third, we combine our ranking formula for the hesitant fuzzy linguistic term sets and the relative comparison rule, we define a ranking method for the hesitant fuzzy linguistic term sets. The detailed process are shown as follows:

The ranking formula of two hesitant fuzzy linguistic term sets $H_{S}^{1}$ and $H_{S}^{2}$ is defined as follows:

Definition 6. Let the $H_{S}^{1}$ and $H_{S}^{2}$ are two hesitant fuzzy linguistic term sets. The ranking formula of 
$H_{S}^{1}$ and $H_{S}^{2}$ are defined as

$$
p\left(H_{S}^{1} \geqslant H_{S}^{2}\right)=\frac{\max \left\{I\left(H_{S}^{1+}\right)-I\left(H_{S}^{2+}\right), 0\right\}+\max \left\{I\left(H_{S}^{1-}\right)-I\left(H_{S}^{2-}\right), 0\right\}+0.5 N\left(H_{S}^{1} \cap H_{S}^{2}\right)}{\left|\left(I\left(H_{S}^{1+}\right)-I\left(H_{S}^{2+}\right)\right)\right|+\left|\left(I\left(H_{S}^{1-}\right)-I\left(H_{S}^{2-}\right)\right)\right|+N\left(H_{S}^{1} \cap H_{S}^{2}\right)}
$$

and

$$
p\left(H_{S}^{2} \geqslant H_{S}^{1}\right)=\frac{\max \left\{I\left(H_{S}^{2+}\right)-I\left(H_{S}^{1+}\right), 0\right\}+\max \left\{I\left(H_{S}^{2-}\right)-I\left(H_{S}^{1-}\right), 0\right\}+0.5 N\left(H_{S}^{1} \cap H_{S}^{2}\right)}{\left|\left(I\left(H_{S}^{2+}\right)-I\left(H_{S}^{1+}\right)\right)\right|+\left|\left(I\left(H_{S}^{2-}\right)-I\left(H_{S}^{1-}\right)\right)\right|+N\left(H_{S}^{1} \cap H_{S}^{2}\right)}
$$

where $N\left(H_{S}^{1} \cap H_{S}^{2}\right)$ denote the number of the same linguistic term in the hesitant fuzzy linguistic term set $H_{S}^{1}$ and $H_{S}^{2}$.

Based on the Equation (10) and (11), we give the Property 1.

Property 1. Let $H_{S}^{1}, H_{S}^{2}$ and $H_{S}^{3}$ be any three hesitant fuzzy linguistic term sets. Then

(i) (Normalization): $0 \leqslant p\left(H_{S}^{1} \geqslant H_{S}^{2}\right) \leqslant 1$;

(ii) (Visualizability): If $H_{S}^{1-}>H_{S}^{2+}$, then $p\left(H_{S}^{1} \geqslant H_{S}^{2}\right)=1$; if $H_{S}^{1+}<H_{S}^{2-}$, then $p\left(H_{S}^{1} \geqslant H_{S}^{2}\right)=$ 0 ;

(iii) (Complementarity): $p\left(H_{S}^{1} \geqslant H_{S}^{2}\right)+p\left(H_{S}^{2} \geqslant H_{S}^{1}\right)=1$;

(iv) (Reflexivity): If $H_{S}^{1}=H_{S}^{2}$, then $p\left(H_{S}^{1} \geqslant H_{S}^{2}\right)=p\left(H_{S}^{2} \geqslant H_{S}^{1}\right)=0.5$;

(v) (Transitivity): If $p\left(H_{S}^{1} \geqslant H_{S}^{2}\right) \geqslant 0.5, p\left(H_{S}^{2} \geqslant H_{S}^{3}\right) \geqslant 0.5$, then $p\left(H_{S}^{1} \geqslant H_{S}^{3}\right) \geqslant 0.5$;

Proof: According to the Equation (10), $0 \leqslant p\left(H_{S}^{1} \geqslant H_{S}^{2}\right) \leqslant 1$ is obvious. For the item (ii), according to the Equation (10) and $H_{S}^{1-}>H_{S}^{2+}$, we get

$$
p\left(H_{S}^{1} \geqslant H_{S}^{2}\right)=\frac{I\left(H_{S}^{1+}\right)-I\left(H_{S}^{2+}\right)+I\left(H_{S}^{1-}\right)-I\left(H_{S}^{2-}\right)+0.5 \times 0}{\left|\left(I\left(H_{S}^{1+}\right)-I\left(H_{S}^{2+}\right)\right)\right|+\left|\left(I\left(H_{S}^{1-}\right)-I\left(H_{S}^{2-}\right)\right)\right|+0}=1
$$

next, according to the Equation (10) and $H_{S}^{1+}<H_{S}^{2-}$, we get

$$
p\left(H_{S}^{1} \geqslant H_{S}^{2}\right)=\frac{0+0+0.5 \times 0}{\left|\left(I\left(H_{S}^{1+}\right)-I\left(H_{S}^{2+}\right)\right)\right|+\left|\left(I\left(H_{S}^{1-}\right)-I\left(H_{S}^{2-}\right)\right)\right|+0}=0
$$

Then, the item (ii) is hold. For the item (iii), according to the Equation (10) and (11), we get

$$
\begin{aligned}
p\left(H_{S}^{1} \geqslant\right. & \left.H_{S}^{2}\right)+p\left(H_{S}^{2} \geqslant H_{S}^{1}\right)= \\
& =\frac{\max \left\{I\left(H_{S}^{1+}\right)-I\left(H_{S}^{2+}\right), 0\right\}+\max \left\{I\left(H_{S}^{1-}\right)-I\left(H_{S}^{2-}\right), 0\right\}+0.5 N\left(H_{S}^{1} \cap H_{S}^{2}\right)}{\left|\left(I\left(H_{S}^{2+}\right)-I\left(H_{S}^{1+}\right)\right)\right|+\left|\left(I\left(H_{S}^{2-}\right)-I\left(H_{S}^{1-}\right)\right)\right|+N\left(H_{S}^{1} \cap H_{S}^{2}\right)}+
\end{aligned}
$$




$$
\begin{aligned}
& \frac{\max \left\{I\left(H_{S}^{2+}\right)-I\left(H_{S}^{1+}\right), 0\right\}+\max \left\{I\left(H_{S}^{2-}\right)-I\left(H_{S}^{1-}\right), 0\right\}+0.5 N\left(H_{S}^{1} \cap H_{S}^{2}\right)}{\left|\left(I\left(H_{S}^{2+}\right)-I\left(H_{S}^{1+}\right)\right)\right|+\left|\left(I\left(H_{S}^{2-}\right)-I\left(H_{S}^{1-}\right)\right)\right|+N\left(H_{S}^{1} \cap H_{S}^{2}\right)} \\
=1 &
\end{aligned}
$$

Then, the item (iii) is hold. For the item (iv), according to the $H_{S}^{1}=H_{S}^{2}$ and the Equation (10) and (11), we get

$$
\begin{aligned}
p\left(H_{S}^{1} \geqslant H_{S}^{2}\right) & =\frac{\max \left\{I\left(H_{S}^{1+}\right)-I\left(H_{S}^{2+}\right), 0\right\}+\max \left\{I\left(H_{S}^{1-}\right)-I\left(H_{S}^{2-}\right), 0\right\}+0.5 N\left(H_{S}^{1} \cap H_{S}^{2}\right)}{\left|\left(I\left(H_{S}^{2+}\right)-I\left(H_{S}^{1+}\right)\right)\right|+\left|\left(I\left(H_{S}^{2-}\right)-I\left(H_{S}^{1-}\right)\right)\right|+N\left(H_{S}^{1} \cap H_{S}^{2}\right)} \\
& =\frac{0+0+0.5 N\left(H_{S}^{1} \cap H_{S}^{2}\right)}{0+0+N\left(H_{S}^{1} \cap H_{S}^{2}\right)} \\
& =0.5 \\
p\left(H_{S}^{2} \geqslant H_{S}^{1}\right) & =\frac{\max \left\{I\left(H_{S}^{2+}\right)-I\left(H_{S}^{1+}\right), 0\right\}+\max \left\{I\left(H_{S}^{2-}\right)-I\left(H_{S}^{1-}\right), 0\right\}+0.5 N\left(H_{S}^{1} \cap H_{S}^{2}\right)}{\left|\left(I\left(H_{S}^{2+}\right)-I\left(H_{S}^{1+}\right)\right)\right|+\left|\left(I\left(H_{S}^{2-}\right)-I\left(H_{S}^{1-}\right)\right)\right|+N\left(H_{S}^{1} \cap H_{S}^{2}\right)} \\
& =\frac{0+0+0.5 N\left(H_{S}^{1} \cap H_{S}^{2}\right)}{0+0+N\left(H_{S}^{1} \cap H_{S}^{2}\right)} \\
& =0.5
\end{aligned}
$$

Then, the item (iv) is hold. For the item $(v)$, according to the $p\left(H_{S}^{1} \geqslant H_{S}^{2}\right) \geqslant 0.5, p\left(H_{S}^{2} \geqslant H_{S}^{3}\right) \geqslant 0.5$ and the Equation (10), we get

$$
\begin{aligned}
& \max \left\{I\left(H_{S}^{1+}\right)-I\left(H_{S}^{2+}\right), 0\right\}+\max \left\{I\left(H_{S}^{1-}\right)-I\left(H_{S}^{2-}\right), 0\right\} \\
& \geqslant 0.5\left|\left(I\left(H_{S}^{1+}\right)-I\left(H_{S}^{2+}\right)\right)\right|+0.5\left|\left(I\left(H_{S}^{1-}\right)-I\left(H_{S}^{2-}\right)\right)\right|
\end{aligned}
$$

and

$$
\begin{aligned}
& \max \left\{I\left(H_{S}^{2+}\right)-I\left(H_{S}^{3+}\right), 0\right\}+\max \left\{I\left(H_{S}^{2-}\right)-I\left(H_{S}^{3-}\right), 0\right\} \\
& \geqslant 0.5\left|\left(I\left(H_{S}^{2+}\right)-I\left(H_{S}^{3+}\right)\right)\right|+0.5\left|\left(I\left(H_{S}^{2-}\right)-I\left(H_{S}^{3-}\right)\right)\right|
\end{aligned}
$$

then

$$
\begin{aligned}
& \max \left\{I\left(H_{S}^{1+}\right)-I\left(H_{S}^{3+}\right), 0\right\}+\max \left\{I\left(H_{S}^{1-}\right)-I\left(H_{S}^{3-}\right), 0\right\} \\
& \geqslant 0.5\left|\left(I\left(H_{S}^{1+}\right)-I\left(H_{S}^{3+}\right)\right)\right|+0.5\left|\left(I\left(H_{S}^{1-}\right)-I\left(H_{S}^{3-}\right)\right)\right|
\end{aligned}
$$


Next, according to the Equation (10), we get

$$
p\left(H_{S}^{1} \geqslant H_{S}^{3}\right)=\frac{\max \left\{I\left(H_{S}^{1+}\right)-I\left(H_{S}^{3+}\right), 0\right\}+\max \left\{I\left(H_{S}^{1-}\right)-I\left(H_{S}^{3-}\right), 0\right\}+0.5 N\left(H_{S}^{1} \cap H_{S}^{3}\right)}{\left|\left(I\left(H_{S}^{1+}\right)-I\left(H_{S}^{3+}\right)\right)\right|+\left|\left(I\left(H_{S}^{1-}\right)-I\left(H_{S}^{3-}\right)\right)\right|+N\left(H_{S}^{1} \cap H_{S}^{3}\right)}
$$

$\geqslant 0.5$

Then, the (iv) is hold.

We give some discussion for the ranking formula of the hesitant fuzzy linguistic term sets.

Example 1 Assume that there is a linguistic term set $S=\left\{s_{0}, \ldots, s_{6}\right\}, H_{S}^{1}=\left\{s_{3}, s_{4}, s_{5}\right\}$ and $H_{S}^{2}=\left\{s_{5}, s_{6}\right\}$ are two hesitant fuzzy linguistic term sets on $S$.

Based on the Equation (1)-(2), we get

$$
\begin{gathered}
p_{R}\left(H_{S}^{1} \geqslant H_{S}^{2}\right)=\frac{\max (0,5-5)-\max (0,3-6)}{(5-3)+(6-5)}=0 \\
p_{L}\left(H_{S}^{1} \geqslant H_{S}^{2}\right)=\max \left\{1-\max \left(\frac{6-3}{(5-3)+(6-5)}, 0\right)\right\}=0
\end{gathered}
$$

and the $H_{S}^{1}=H_{S}^{2}$. However, $H_{S}^{1}$ is not equal to $H_{S}^{2}$. Therefore, the Equation (1)-(2) is not reasonable in some situation. Next, according to Equation (3) and (10), we get

$$
p_{w}\left(H_{S}^{1} \geqslant H_{S}^{2}\right)=\frac{0.5(5-5+1)}{6-3+1}=\frac{1}{4}
$$

and

$$
p\left(H_{S}^{1} \geqslant H_{S}^{2}\right)=\frac{\max \{5-6,0\}+\max \{3-5,0\}+0.5 \times 1}{|5-6|+|3-5|+1}=\frac{1}{8}
$$

However, according to the $H_{S}^{1}=\left\{s_{3}, s_{4}, s_{5}\right\}$ and $H_{S}^{2}=\left\{s_{5}, s_{6}\right\}$, we find the $H_{S}^{1} \cap H_{S}^{2}=s_{5}$ and $H_{S}^{1} \cup H_{S}^{2}=\left\{s_{3}, s_{4}, s_{5}, s_{6}\right\}$. If the each linguistic term of $H_{S}^{1} \cup H_{S}^{2}$ denote the $\frac{1}{4}$, then $s_{5}$ also denote $\frac{1}{4}$. But, according to the $H_{S}^{1} \cap H_{S}^{2}=s_{5}$, then $s_{5}$ denote $\frac{1}{4} \times \frac{1}{2}=\frac{1}{8}$. Further, $p\left(H_{S}^{1} \geqslant H_{S}^{2}\right)=\frac{1}{8}$ is more rational than $p\left(H_{S}^{1} \geqslant H_{S}^{2}\right)=\frac{1}{4}$.

Example 2 Assume that there is a linguistic term set $S=\left\{s_{0}, \ldots, s_{6}\right\}, H_{S}^{1}=\left\{s_{4}, s_{5}\right\}$ and $H_{S}^{2}=\left\{s_{2}, s_{3}\right\}$ are two hesitant fuzzy linguistic term sets on $S$.

Based on the Equation (1)-(3) and (10), we get 


$$
\begin{gathered}
p_{R}\left(H_{S}^{1} \geqslant H_{S}^{2}\right)=\frac{\max (0,5-2)-\max (0,4-3)}{(5-4)+(3-2)}=1 \\
p_{L}\left(H_{S}^{1} \geqslant H_{S}^{2}\right)=\max \left\{1-\max \left(\frac{3-4}{(5-4))+(3-2)}, 0\right)\right\}=1 \\
p_{w}\left(H_{S}^{1} \geqslant H_{S}^{2}\right)=1 \\
p\left(H_{S}^{1} \geqslant H_{S}^{2}\right)=\frac{\max \{5-3,0\}+\max \{4-2,0\}+0.5 \times 0}{|5-3|+|4-2|+0}=1
\end{gathered}
$$

Based on the ranking result of Example 1 and 2 under the different comparison relation between two hesitant fuzzy linguistic term sets, we find that our ranking formula is rational and easy understand.

Definition 7. The ranking rule of two hesitant fuzzy linguistic term sets $H_{S}^{1}$ and $H_{S}^{2}$ are defined as:

(i) If $p\left(H_{S}^{1} \geqslant H_{S}^{2}\right)>0.5$, then $H_{S}^{1}>H_{S}^{2}$.

(ii) If $p\left(H_{S}^{1} \geqslant H_{S}^{2}\right)<0.5$, then $H_{S}^{1}<H_{S}^{2}$.

(iii) If $p\left(H_{S}^{1} \geqslant H_{S}^{2}\right)=0.5$, then $H_{S}^{1}=H_{S}^{2}$.

where $p\left(H_{S}^{1} \geqslant H_{S}^{2}\right)$ obtained by Equation (10).

\subsection{The application of prospect theory}

In this section, we will apply the prospect theory to aggregate hesitant linguistic fuzzy evaluation information and interval probability. First, we define a relative distance between the hesitant fuzzy linguistic term sets by the our ranking formula for the hesitant fuzzy linguistic term sets. Second, we use our ranking method, our relative distance and prospect theory to get the interval individual prospect theory value. Third, we use the average operator to get the interval comprehensive prospect value. The detailed process are shown as follows:

According to the Equation (10) and (11), we give the definition of the relative distance formula of hesitant fuzzy linguistic term sets.

Definition 8. Let the $H_{S}^{1}$ and $H_{S}^{2}$ are two hesitant fuzzy linguistic term sets. The relative distance formula of hesitant fuzzy linguistic term set is defined as 


$$
d\left(H_{S}^{1}, H_{S}^{2}\right)=\left|p\left(H_{S}^{1} \geqslant H_{S}\right)-p\left(H_{S}^{2} \geqslant H_{S}\right)\right|
$$

where $H_{S}=\left\{s_{0}, s_{1}, s_{2}, s_{3}, s_{4}, s_{5}, s_{6}\right\}$.

Based on the Equation (12), we give the Property 2.

Property 2. Let $H_{S}^{1}, H_{S}^{2}$ and $H_{S}^{3}$ be any three hesitant fuzzy linguistic term sets. Then

(i) $0 \leqslant d\left(H_{S}^{1}, H_{S}^{2}\right) \leqslant 1$;

(ii) $d\left(H_{S}^{1}, H_{S}^{2}\right)=d\left(H_{S}^{2}, H_{S}^{1}\right)$;

(iii) $d\left(H_{S}^{1}, H_{S}^{2}\right) \leqslant d\left(H_{S}^{1}, H_{S}^{3}\right)+d\left(H_{S}^{3}, H_{S}^{2}\right)$.

Proof: According to the Equation (12), $0 \leqslant d\left(H_{S}^{1}, H_{S}^{2}\right) \leqslant 1$ and $d\left(H_{S}^{1}, H_{S}^{2}\right)=d\left(H_{S}^{2}, H_{S}^{1}\right)$ is apparent. For the item (iii),

$$
\begin{aligned}
d\left(H_{S}^{1}, H_{S}^{2}\right) & =\left|p\left(H_{S}^{1} \geqslant H_{S}\right)-p\left(H_{S}^{1} \geqslant H_{S}\right)\right| \\
& =\left|p\left(H_{S}^{1} \geqslant H_{S}\right)-p\left(H_{S}^{3} \geqslant H_{S}\right)+p\left(H_{S}^{3} \geqslant H_{S}\right)-p\left(H_{S}^{2} \geqslant H_{S}\right)\right| \\
& \leqslant\left|p\left(H_{S}^{1} \geqslant H_{S}\right)-p\left(H_{S}^{3} \geqslant H_{S}\right)\right|+\left|p\left(H_{S}^{3} \geqslant H_{S}\right)-p\left(H_{S}^{2} \geqslant H_{S}\right)\right| \\
& =d\left(H_{S}^{1}, H_{S}^{3}\right)+d\left(H_{S}^{3}, H_{S}^{2}\right)
\end{aligned}
$$

That is, $d\left(H_{S}^{1}, H_{S}^{2}\right) \leqslant d\left(H_{S}^{1}, H_{S}^{3}\right)+d\left(H_{S}^{3}, H_{S}^{2}\right)$ holds.

Next, according to the Equation (6)-(12), we will apply the prospect theory to aggregate the hesitant fuzzy linguistic evaluation information and interval probability. The detailed steps are shown as follows:

- The value of gain and loss.

The gain $G_{i j}^{t}(1 \leqslant i \leqslant n, 1 \leqslant j \leqslant m, 1 \leqslant t \leqslant f)$ is defined as

$$
G_{i j}^{t}=\left(d\left(\bar{x}_{i j}^{t}, \bar{r}_{j}^{t}\right)\right)^{\alpha}, \bar{x}_{i j}^{t} \geqslant \bar{r}_{j}^{t}
$$

The loss $L_{i j}^{t}(1 \leqslant i \leqslant n, 1 \leqslant j \leqslant m, 1 \leqslant t \leqslant f)$ is defined as

$$
L_{i j}^{t}=-\lambda\left(d\left(\bar{x}_{i j}^{t}, \bar{r}_{j}^{t}\right)\right)^{\beta}, \bar{x}_{i j}^{t}<\bar{r}_{j}^{t}
$$

Here, according to definition 6 , the comparative rule of $\bar{x}_{i j}^{t}$ and $\bar{r}_{j}^{t}$ are defined as 
(i) If $p\left(\bar{x}_{i j}^{t} \geqslant \bar{r}_{j}^{t}\right)>0.5$, then $\bar{x}_{i j}^{t}>\bar{r}_{j}^{t}$.

(ii) If $p\left(\bar{x}_{i j}^{t} \geqslant \bar{r}_{j}^{t}\right)<0.5$, then $\bar{x}_{i j}^{t}<\bar{r}_{j}^{t}$.

(iii) If $p\left(\bar{x}_{i j}^{t} \geqslant \bar{r}_{j}^{t}\right)=0.5$, then $\bar{x}_{i j}^{t}=\bar{r}_{j}^{t}$.

According to the Equation (12), $d\left(\bar{x}_{i j}^{t}, \bar{r}_{j}^{t}\right)$ is defined as

$$
d\left(\bar{x}_{i j}^{t}, \bar{r}_{j}^{t}\right)=\left|p\left(\bar{x}_{i j}^{t} \geqslant H_{S}\right)-p\left(\bar{r}_{j}^{t} \geqslant H_{S}\right)\right|
$$

where $\bar{x}_{i j}^{t}$ and $\bar{r}_{j}^{t}$ are both the hesitant fuzzy linguistic term sets; $p\left(\bar{x}_{i j}^{t} \geqslant H_{S}\right)$ and $p\left(\bar{r}_{j}^{t} \geqslant H_{S}\right)$ are obtained by the Equation (10) and (11).

- The interval probability weight of the gain and the loss.

The interval probability weight $\pi_{i j}^{t+}=\left[\pi_{i j}^{t+-}, \pi_{i j}^{t++}\right]$, which is the interval number, of the gain.

$$
\begin{aligned}
\pi_{i j}^{t+-} & =\frac{\left(P_{t}^{-}\right)^{\gamma}}{\left[\left(P_{t}^{-}\right)^{\gamma}+\left(1-P_{t}^{-}\right)^{\gamma}\right]^{1 / \gamma}} \\
\pi_{i j}^{t++} & =\frac{\left(P_{t}^{+}\right)^{\gamma}}{\left[\left(P_{t}^{+}\right)^{\gamma}+\left(1-P_{t}^{+}\right)^{\gamma}\right]^{1 / \gamma}}
\end{aligned}
$$

The interval probability weight $\pi_{i j}^{t-}=\left[\pi_{i j}^{t--}, \pi_{i j}^{t-+}\right]$, which is the interval number, of the loss.

$$
\begin{aligned}
\pi_{i j}^{t--} & =\frac{\left(P_{t}^{-}\right)^{\delta}}{\left[\left(P_{t}^{-}\right)^{\delta}+\left(1-P_{t}^{-}\right)^{\delta}\right]^{1 / \delta}} \\
\pi_{i j}^{t-+} & =\frac{\left(P_{t}^{+}\right)^{\delta}}{\left[\left(P_{t}^{+}\right)^{\delta}+\left(1-P_{t}^{+}\right)^{\delta}\right]^{1 / \delta}}
\end{aligned}
$$

where $\gamma$ and $\delta$ are parameters that represent the degree of curvature of the interval probability weight function of gain and loss, respectively, and $\gamma>0$ and $\delta>0, \alpha=\beta=0.88, \lambda=2.25$, $\gamma=0.61$ and $\delta=0.69$, which will be adopted in our case study in section 7 .

- The interval individual prospect value $\bar{U}_{i j}=\left[U_{i j}^{-}, U_{i j}^{+}\right](1 \leqslant i \leqslant n, 1 \leqslant j \leqslant m)$, which are the interval numbers.

$$
\begin{aligned}
& U_{i j}^{+*}=\sum_{t=1}^{f} G_{i j}^{t} \pi_{i j}^{t++}+\sum_{t=1}^{f} L_{i j}^{t} \pi_{i j}^{t-+} \\
& U_{i j}^{-*}=\sum_{t=1}^{f} G_{i j}^{t} \pi_{i j}^{t+-}+\sum_{t=1}^{f} L_{i j}^{t} \pi_{i j}^{t--}
\end{aligned}
$$




$$
\begin{aligned}
& U_{i j}^{+}=\max \left\{U_{i j}^{t+*}, U_{i j}^{t-*}\right\} \\
& U_{i j}^{-}=\max \left\{U_{i j}^{t+*}, U_{i j}^{t-*}\right\}
\end{aligned}
$$

According to the Equation (10)-(22) and Table 1, we get the interval individual prospect theory value $\bar{U}_{i j}^{t}$ of each alternatives $A_{i}(1 \leqslant i \leqslant n)$. Meanwhile, according to the following equation

$$
\bar{U}_{i}=\sum_{j=1}^{m} \frac{\bar{U}_{i j}}{m}
$$

and the interval individual prospect theory value $\bar{U}_{i j}$, we get the interval comprehensive prospect value $\bar{U}_{i}$ of each alternatives $A_{i}(1 \leqslant i \leqslant n)$, which are also the interval numbers.

Next, we will defined a new ranking method of interval number, which is named as the priority degree method for interval numbers, to obtaining the ranking of $\bar{U}_{i}(1 \leqslant i \leqslant n)$.

\section{The priority degree method of interval number is applied to rank interval comprehensive prospect value}

In this section, we use the priority degree of interval number to rank interval comprehensive prospect value. First, we give a new ranking method for interval number, which is named as the priority degree method of interval number. Second, we introduce the ranking steps of the interval comprehensive prospect value $\bar{U}_{i}(1 \leqslant i \leqslant n)$ by the priority degree method of interval number. The detailed steps are shown as the follows:

\subsection{The priority degree method for interval number}

In this section, we will a ranking method for interval number, which is named as the priority degree method for interval number. First, we define a priority degree formula for interval number. Second, we combine the Boolean matrix and priority degree matrix, we propose the priority degree method for interval number. Third, we introduce the relationship between the our priority degree method and the existing ranking method for interval number ${ }^{47,48}$. The detailed process are shown as follows: 
The priority degree method for interval number is defined as follows:

Considering the existing possibility degree formula only use the endpoints of interval numbers, but do not fully use the internal information of interval numbers. To fully use the interval information of interval numbers, we choose the interval number as the integral range of an integral function, and use the size of area to express the relationship between interval numbers. That is, the larger the interval numbers is, the larger the area is.

Definition 9. If the integral function $g(x)$ satisfies the following four items:

(i) Strictly increasing for the integral result of $g(x)$ in the domain $(-\infty,+\infty)$;

(ii) $g(0) \neq 0$;

(iii) The range is $(0,+\infty)$;

Then $g(x)$ called be the priority degree function for the interval number.

Based on this priority degree function $g(x)$ and the ideas, which choose the interval number as the integral range of an integral function, and use the size of area to express the relationship between interval numbers, we define the following formula.

Definition 10. Let $\bar{a}=\left[a_{1}^{-}, a_{1}^{+}\right]$and $\bar{a}_{2}=\left[a_{2}^{-}, a_{2}^{+}\right]$be two interval numbers and

$$
h\left(\bar{a}_{1}>\bar{a}_{2}\right)=\frac{\int_{0}^{1} g\left(m_{\lambda}\left(\bar{a}_{1}\right)\right) d \lambda}{\int_{0}^{1} g\left(m_{\lambda}\left(\bar{a}_{2}\right)\right) d \lambda}
$$

where $m_{\lambda}\left(\bar{a}_{1}\right)=a_{1}^{-}+\lambda \operatorname{len}\left(\bar{a}_{1}\right), m_{\lambda}\left(\bar{a}_{2}\right)=a_{2}^{-}+\lambda \operatorname{len}\left(\bar{a}_{2}\right)$, and $\lambda \in[0,1], \operatorname{len}\left(\bar{a}_{1}\right)=a_{1}^{+}-a_{1}^{-}$, $\operatorname{len}\left(\bar{a}_{2}\right)=a_{2}^{+}-a_{2}^{-}$. If $h\left(\bar{a}_{1}>\bar{a}_{2}\right)>1, h\left(\bar{a}_{1}>\bar{a}_{2}\right)$ expresses the comparison between interval numbers $\bar{a}_{1}$ and $\bar{a}_{2}, \bar{a}_{1}$ is better than $\bar{a}_{2}$. If $h\left(\bar{a}_{1}>\bar{a}_{2}\right)<1, h\left(\bar{a}_{1}>\bar{a}_{2}\right)$ expresses the comparison between interval numbers $\bar{a}_{1}$ and $\bar{a}_{2}, \bar{a}_{2}$ is better than $\bar{a}_{1}$.

For convenience, let $g(x)=e^{x}$, so that Equation (24) can be expressed as

$$
h\left(\bar{a}_{1}>\bar{a}_{2}\right)= \begin{cases}\frac{\operatorname{len}\left(\bar{a}_{2}\right)}{\operatorname{len}\left(\bar{a}_{1}\right)} \frac{\left(e^{a_{1}^{+}}-e^{a_{1}^{-}}\right)}{\left(e^{a_{2}^{+}}-e^{a_{2}^{-}}\right)} & \operatorname{len}\left(\bar{a}_{1}\right) \neq 0, \operatorname{len}\left(\bar{a}_{2}\right) \neq 0 \\ \frac{\operatorname{len}\left(\bar{a}_{2}\right) e^{a_{1}^{-}}}{\left(e_{2}^{+}-e^{a_{2}^{-}}\right)} & \operatorname{len}\left(\tilde{a}_{1}\right)=0, \operatorname{len}\left(\bar{a}_{2}\right) \neq 0 \\ \frac{\left(e_{1}^{+}-e^{a_{1}^{-}}\right)}{\operatorname{len}\left(a_{1}\right) e^{a_{2}^{-}}} & \operatorname{len}\left(\bar{a}_{1}\right) \neq 0, \operatorname{len}\left(\bar{a}_{2}\right)=0 \\ \frac{e_{1}^{a_{1}^{-}}}{e^{a_{1}^{-}}} & \operatorname{len}\left(\bar{a}_{1}\right)=0, \operatorname{len}\left(\bar{a}_{2}\right)=0\end{cases}
$$


Based on the Equation (24) and (25), we give the Property 3.

Property 3. Let three interval numbers $\bar{a}_{1}=\left[a_{1}^{-}, a_{1}^{+}\right], \bar{a}_{2}=\left[a_{2}^{-}, a_{2}^{+}\right]$, and $\bar{a}_{3}=\left[a_{3}^{-}, a_{3}^{+}\right]$.

(i) $h\left(\bar{a}_{1}>\bar{a}_{2}\right)>0$;

(ii) $h\left(\bar{a}_{1}>\bar{a}_{2}\right) h\left(\bar{a}_{2}>\bar{a}_{1}\right)=1$;

(iii) $h\left(\bar{a}_{1}>\bar{a}_{1}\right)=1$;

(iv) (Transitivity) If $h\left(\bar{a}_{1}>\bar{a}_{2}\right) \geqslant 1$ and $h\left(\bar{a}_{2}>\bar{a}_{3}\right) \geqslant 1, h\left(\bar{a}_{1}>\bar{a}_{3}\right) \geqslant 1$.

According to the Equation (24) and (25), we get that the proof of items (i)-(iv) is obvious.

Let $\bar{a}_{1}, \bar{a}_{2}, \ldots, \bar{a}_{n}$ be $n$ interval numbers, we introduce the priority degree method for interval numbers. The detailed steps as follows:

1. According to the Equation (25), we construct the priority matrix $H=\left(h_{i k}\right)_{n \times n}$.

$$
H=\left(\begin{array}{cccc}
h_{11} & h_{12} & \ldots & h_{1 n} \\
h_{21} & h_{22} & \ldots & h_{2 n} \\
\ldots & \ldots & \ldots & \ldots \\
h_{n 1} & h_{n 2} & \ldots & h_{n n}
\end{array}\right)
$$

2. According to the following formula and $\operatorname{Ref}^{50}$,

$$
q_{i k}= \begin{cases}1 & h_{i k} \geqslant 1 \\ 0 & h_{i k}<1\end{cases}
$$

we get the Boolean matrix $Q=\left(q_{i k}\right)_{n \times n}$.

$$
Q=\left(\begin{array}{cccc}
q_{11} & q_{12} & \ldots & q_{1 n} \\
q_{21} & q_{22} & \ldots & q_{2 n} \\
\ldots & \ldots & \ldots & \ldots \\
q_{n 1} & q_{n 2} & \ldots & q_{n n}
\end{array}\right)
$$

3. According to the following formula and $\operatorname{Ref}{ }^{50}$,

$$
\lambda_{i}=\sum_{j=1}^{n} q_{i k}
$$


we get the ranking result for interval numbers $\bar{a}_{i}(i=1,2, \ldots, n)$, then the bigger the values of $\lambda_{i}$, the better $\bar{a}_{i}(i=1,2, \ldots, n)$.

Example 2 Let three interval numbers $\bar{a}_{1}=[2,3], \bar{a}_{2}=[4,7]$ and $\bar{a}_{3}=[5,6]$.

We use the priority degree method for interval numbers to get the ranking result for example 2 .

1. According to the Equation (25), we construct the priority degree matrix $H=\left(h_{i k}\right)_{3 \times 3}$.

$$
\begin{aligned}
& h_{11}=1, h_{12}=\frac{3 e^{3}-3 e^{2}}{e^{7}-e^{4}}, h_{13}=\frac{e^{3}-e^{2}}{e^{6}-e^{5}}, h_{21}=\frac{1}{3} \frac{e^{7}-e^{4}}{e^{3}-e^{2}}, h_{22}=1, h_{23}=\frac{1}{3} \frac{e^{7}-e^{4}}{e^{6}-e^{5}}, h_{31}=\frac{e^{6}-e^{5}}{e^{3}-e^{2}}, \\
& h_{32}=\frac{3 e^{6}-3 e^{5}}{e^{7}-e^{4}}, h_{33}=1 .
\end{aligned}
$$

$$
H=\left(\begin{array}{ccc}
1 & \frac{3 e^{3}-3 e^{2}}{e^{7}-e^{4}} & \frac{e^{3}-e^{2}}{e^{6}-e^{5}} \\
\frac{1}{3} \frac{e^{7}-e^{4}}{e^{3}-e^{2}} & 1 & \frac{1}{3} \frac{e^{7}-e^{4}}{e^{6}-e^{5}} \\
\frac{e^{6}-e^{5}}{e^{3}-e^{2}} & \frac{3 e^{6}-3 e^{5}}{e^{7}-e^{4}} & 1
\end{array}\right)
$$

2. According to the Equation (26), we construct the fuzzy complementary judgement matrix $Q=$ $\left(q_{i k}\right)_{3 \times 3}$.

$$
Q=\left(\begin{array}{lll}
1 & 0 & 0 \\
1 & 1 & 1 \\
1 & 0 & 1
\end{array}\right)
$$

3. According to the Equation (27), the ranking result for interval numbers $\bar{a}_{1}, \bar{a}_{2}$ and $\bar{a}_{3}$ is $\bar{a}_{1}<$ $\bar{a}_{2}<\bar{a}_{3}$.

We give some discussion for the priority degree method.

(a) According to the Example 2 (which denote the special situation) and Table 2, we know that the existing possibility degree method, which proposed by the Equation (4) and (5), don't get ranking result of interval numbers $\bar{a}_{2}$ and $\bar{a}_{3}$. However, our priority degree method can get the ranking result of interval numbers $\bar{a}_{2}$ and $\bar{a}_{3}$. According to the Example 3 (which denote the general situation) and Table 2, we know that the ranking result of our priority degree method is the same as the ranking result of the existing possibility degree method. Then, our priority degree method is more rational than the existing possibility degree method of interval number. 
Table 2: The relationship between our priority degree method and the existing possibility degree method

\begin{tabular}{c|ccc}
\hline Example & Equation (25) & Equation (4) & Equation (5) \\
\hline Example 2: $\bar{a}_{1}=[2,3], \bar{a}_{2}=[4,7]$ and $\bar{a}_{3}=[5,6]$ & $\bar{a}_{1}<\bar{a}_{2}<\bar{a}_{3}$ & $\bar{a}_{1}<\bar{a}_{2}=\bar{a}_{3}$ & $\bar{a}_{1}<\bar{a}_{2}=\bar{a}_{3}$ \\
Example 3: $\bar{a}_{1}=[1,2], \bar{a}_{2}=[4,5]$ and $\bar{a}_{3}=[7,8]$ & $\bar{a}_{1}<\bar{a}_{2}<\bar{a}_{3}$ & $\bar{a}_{1}<\bar{a}_{2}<\bar{a}_{3}$ & $\bar{a}_{1}<\bar{a}_{2}<\bar{a}_{3}$ \\
\hline
\end{tabular}

(b) The possibility degree method of References ${ }^{48,49}$ only use the endpoints of interval numbers, but it do not fully use the internal information of interval numbers. However, our priority degree method fully use the internal information of interval numbers. This greatly reduces the loss of information.

\subsection{The application of priority degree method for interval number}

In this section, we will use the priority degree method for interval number to rank interval comprehensive prospect value. The detailed process are shown as follows:

According to the Equation (25)-(27), we will introduce the ranking method of interval comprehensive prospect value $\bar{U}_{i}=\left[U_{i}^{-}, U_{i}^{+}\right](1 \leqslant i \leqslant n)$. The detailed steps are shown as follows:

- According to the Equation (25), we use

$$
h\left(\bar{U}_{i}>\bar{U}_{j}\right)= \begin{cases}\frac{\operatorname{len}\left(\bar{U}_{j}\right)}{\operatorname{len}\left(\bar{U}_{i}\right)} \frac{\left(e^{U_{i}^{+}}-e^{U_{i}^{-}}\right)}{\left(e^{U_{j}^{+}}-e^{U_{j}^{-}}\right)} & \operatorname{len}\left(\bar{U}_{i}\right) \neq 0, \operatorname{len}\left(\bar{U}_{j}\right) \neq 0 \\ \frac{\operatorname{len}\left(\bar{U}_{j}\right) e^{U_{i}^{-}}}{\left(e_{j}^{+}-e^{U_{j}^{-}}\right.} & \operatorname{len}\left(\bar{U}_{i}\right)=0, \operatorname{len}\left(\bar{U}_{j}\right) \neq 0 \\ \frac{\left(e_{i}^{+}-e^{U_{i}^{-}}\right)}{\operatorname{len}\left(\bar{U}_{i}\right) e^{U_{j}^{-}}} & \operatorname{len}\left(\bar{U}_{i}\right) \neq 0, \operatorname{len}\left(\bar{U}_{j}\right)=0 \\ \frac{e_{i}^{U_{i}^{-}}}{e^{U_{j}^{-}}} & \operatorname{len}\left(\bar{U}_{i}\right)=0, \operatorname{len}\left(\bar{U}_{j}\right)=0\end{cases}
$$

where $\operatorname{len}\left(\bar{U}_{i}\right)=U_{i}^{+}-U_{i}^{-}$and $\operatorname{len}\left(\bar{U}_{j}\right)=U_{j}^{+}-U_{j}^{-}$.

to construct the priority matrix $H^{\bar{U}}=\left(h_{i k}^{\bar{U}}\right)_{n \times n}$.

$$
H^{\bar{U}}=\left(\begin{array}{cccc}
h_{11}^{\bar{U}} & h_{12}^{\bar{U}} & \ldots & h_{1 n}^{\bar{U}} \\
h_{21}^{\bar{U}} & h_{22}^{\bar{U}} & \ldots & h_{2 n}^{\bar{U}} \\
\ldots & \ldots & \ldots & \ldots \\
h_{n 1}^{\bar{U}} & h_{n 2}^{\bar{U}} & \ldots & h_{n n}^{\bar{U}}
\end{array}\right)
$$


- According to the Equation (26) and the priority degree matrix $H^{\bar{U}}=\left(h_{i k}^{\bar{U}}\right)_{n \times n}$, we apply

$$
q_{i k}^{\bar{U}}= \begin{cases}1 & h_{i k}^{\bar{U}} \geqslant 1 \\ 0 & h_{i k}^{\bar{U}}<1\end{cases}
$$

to get the Boolean matrix $Q^{\bar{U}}=\left(q_{i k}^{\bar{U}}\right)_{n \times n}$.

$$
Q^{\bar{U}}=\left(\begin{array}{cccc}
q_{11}^{\bar{U}} & q_{12}^{\bar{U}} & \ldots & q_{1 n}^{\bar{U}} \\
q_{21}^{\bar{U}} & q_{22}^{\bar{U}} & \ldots & q_{2 n}^{\bar{U}} \\
\ldots & \ldots & \ldots & \ldots \\
q_{n 1}^{\bar{U}} & q_{n 2}^{\bar{U}} & \ldots & q_{n n}^{\bar{U}}
\end{array}\right)
$$

- According to the Equation (27) and the Boolean matrix $Q^{\bar{U}}=\left(q_{i k}^{\bar{U}}\right)_{n \times n}$, we apply

$$
\lambda_{i}^{\bar{U}}=\sum_{j=1}^{n} q_{i k}^{\bar{U}}
$$

to get $\lambda_{i}^{\bar{U}}(i=1,2, \ldots, n)$.

The result is that the bigger the values of $\lambda_{i}^{\bar{U}}(i=1,2, \ldots, n)$, the better $\bar{U}_{i}(i=1,2, \ldots, n)$. Further, we get the ranking result of alternatives $A_{i}(1 \leqslant i \leqslant n)$ by the ranking result of $\bar{U}_{i}(i=1,2, \ldots, n)$.

\section{The solution of risky hesitant fuzzy linguistic multiple attribute decision making problem}

In this section, we will propose a solution of risky hesitant fuzzy linguistic multiple attribute decision making problem. Based on the section 4 and 5, we give the detailed steps of behavioral risky hesitant fuzzy linguistic multiple attribute decision making with priority degree method.

According to the Equation (12)-(23), (28), (29) and (30), we give the detailed steps of behavioral risky hesitant fuzzy linguistic multiple attribute decision making with priority degree method (as see Figure 1).

Step 1. According to the Equation (12)-(14), we construct the gained matrix $G=\left(G_{i j}^{t}\right)_{n \times m \times f}$ and losing matrix $L=\left(L_{i j}^{t}\right)_{n \times m \times f}$ (Table 3 and 4). 
The evaluation information proposed by the hesitant fuzzy linguistic term set and the probability proposed by the interval number

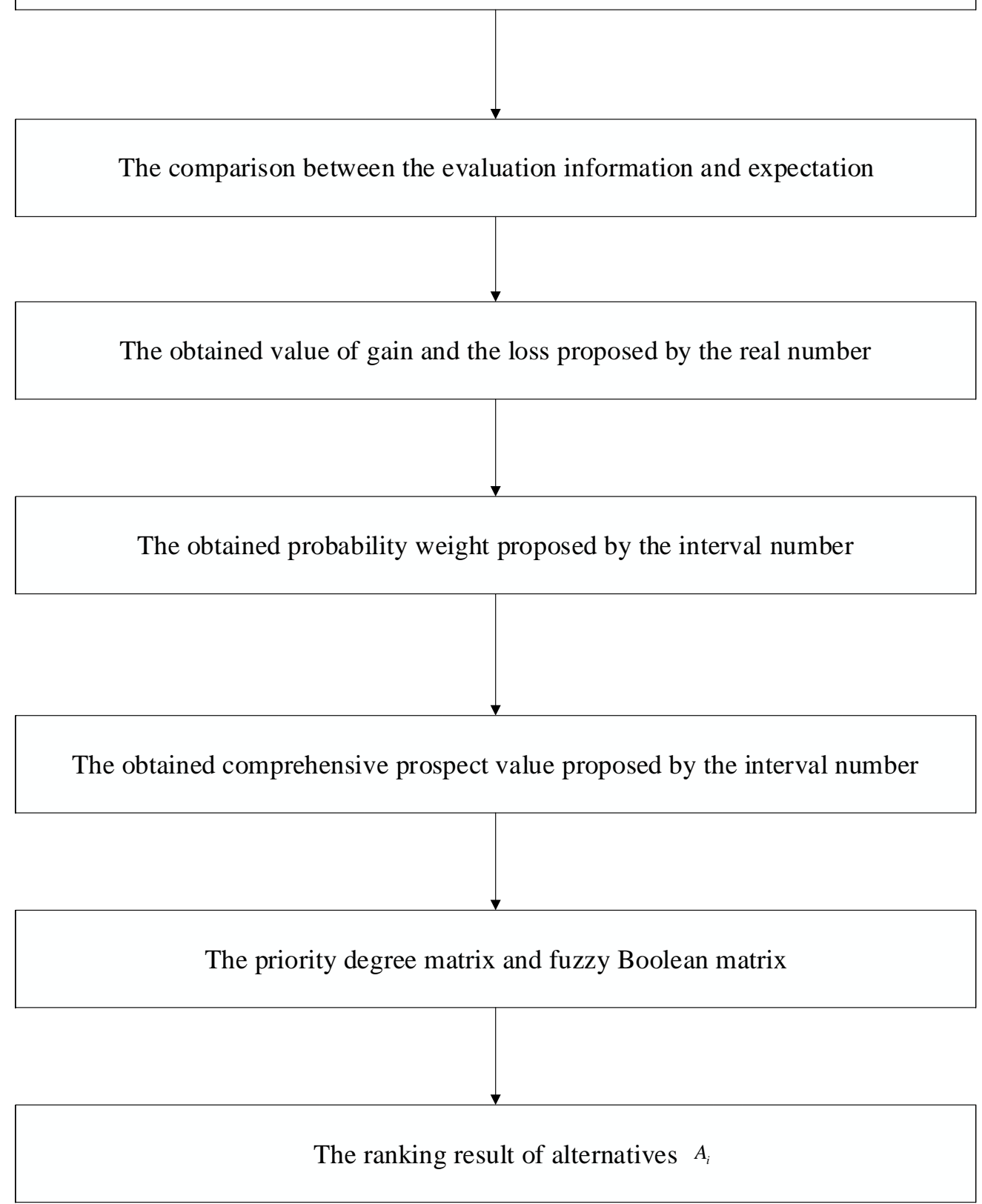

Figure 1: The procedure of behavioral risky hesitant fuzzy linguistic multiple attribute decision making with priority degree method 
Step 2. According to the Equation (15)-(18), we construct the probability weight $\pi_{i j}^{t+}(1 \leqslant i \leqslant$ $n, 1 \leqslant j \leqslant m, 1 \leqslant t \leqslant f)$ of the gain $G_{i j}^{t}(1 \leqslant i \leqslant n, 1 \leqslant j \leqslant m, 1 \leqslant t \leqslant f)$ and the probability weight $\pi_{i j}^{t-}(1 \leqslant i \leqslant n, 1 \leqslant j \leqslant m, 1 \leqslant t \leqslant f)$ of the loss $L_{i j}^{t}(1 \leqslant i \leqslant n, 1 \leqslant j \leqslant m, 1 \leqslant t \leqslant f)$ (Table 5 and 6).

Step 3. According to the Equation (19)-(22), we construct the interval individual prospected

Table 3: The gained matrix $G=\left(G_{i j}^{t}\right)_{n \times m \times f}$

\begin{tabular}{c|ccc|ccc|c|ccc}
\hline Criteria & \multicolumn{3}{|c|}{$C_{1}$} & \multicolumn{3}{c|}{$C_{2}$} & $\ldots$ & \multicolumn{3}{c}{$C_{m}$} \\
\hline State & $T_{1}$ & $\ldots$ & $T_{f}$ & $T_{1}$ & $\ldots$ & $T_{f}$ & $\ldots$ & $T_{1}$ & $\ldots$ & $T_{f}$ \\
\hline$A_{1}$ & $G_{11}^{1}$ & $\ldots$ & $G_{11}^{f}$ & $G_{12}^{1}$ & $\ldots$ & $G_{12}^{f}$ & $\ldots$ & $G_{1 m}^{1}$ & $\ldots$ & $G_{1 m}^{f}$ \\
$A_{2}$ & $G_{21}^{1}$ & $\ldots$ & $G_{21}^{f}$ & $G_{22}^{1}$ & $\ldots$ & $G_{22}^{f}$ & $\ldots$ & $G_{2 m}^{1}$ & $\ldots$ & $G_{2 m}^{f}$ \\
$\ldots$ & $\ldots$ & $\ldots$ & $\ldots$ & $\ldots$ & $\ldots$ & $\ldots$ & $\ldots$ & $\ldots$ & $\ldots$ & $\ldots$ \\
$A_{n}$ & $G_{n 1}^{1}$ & $\ldots$ & $G_{n 1}^{f}$ & $G_{n 2}^{1}$ & $\ldots$ & $G_{n 2}^{f}$ & $\ldots$ & $G_{n m}^{1}$ & $\ldots$ & $G_{n m}^{f}$ \\
\hline
\end{tabular}

Table 4: The losing matrix $L=\left(L_{i j}^{t}\right)_{n \times m \times f}$

\begin{tabular}{c|ccc|ccc|c|ccc}
\hline Criteria & \multicolumn{3}{|c|}{$C_{1}$} & \multicolumn{3}{c|}{$C_{2}$} & $\ldots$ & \multicolumn{3}{c}{$C_{m}$} \\
\hline State & $T_{1}$ & $\ldots$ & $T_{f}$ & $T_{1}$ & $\ldots$ & $T_{f}$ & $\ldots$ & $T_{1}$ & $\ldots$ & $T_{f}$ \\
\hline$A_{1}$ & $L_{11}^{1}$ & $\ldots$ & $L_{11}^{f}$ & $L_{12}^{1}$ & $\ldots$ & $L_{12}^{f}$ & $\ldots$ & $L_{1 m}^{1}$ & $\ldots$ & $L_{1 m}^{f}$ \\
$A_{2}$ & $L_{21}^{1}$ & $\ldots$ & $L_{21}^{f}$ & $L_{22}^{1}$ & $\ldots$ & $L_{22}^{f}$ & $\ldots$ & $L_{2 m}^{1}$ & $\ldots$ & $L_{2 m}^{f}$ \\
$\ldots$ & $\ldots$ & $\ldots$ & $\ldots$ & $\ldots$ & $\ldots$ & $\ldots$ & $\ldots$ & $\ldots$ & $\ldots$ & $\ldots$ \\
$A_{n}$ & $L_{n 1}^{1}$ & $\ldots$ & $L_{n 1}^{f}$ & $L_{n 2}^{1}$ & $\ldots$ & $L_{n 2}^{f}$ & $\ldots$ & $L_{n m}^{1}$ & $\ldots$ & $L_{n m}^{f}$ \\
\hline
\end{tabular}

Table 5: The probability weight $\pi_{i j}^{t-}(1 \leqslant i \leqslant n, 1 \leqslant j \leqslant m, 1 \leqslant t \leqslant f)$

\begin{tabular}{c|ccc|ccc|c|ccc}
\hline Criteria & \multicolumn{3}{|c}{$C_{1}$} & \multicolumn{3}{c|}{$C_{2}$} & $\ldots$ & \multicolumn{3}{c}{$C_{m}$} \\
\hline State & $T_{1}$ & $\ldots$ & $T_{f}$ & $T_{1}$ & $\ldots$ & $T_{f}$ & $\ldots$ & $T_{1}$ & $\ldots$ & $T_{f}$ \\
\hline Probability & $a_{1}$ & $\ldots$ & $a_{f}$ & $a_{1}$ & $\ldots$ & $a_{f}$ & $\ldots$ & $a_{1}$ & $\ldots$ & $a_{f}$ \\
\hline$Z_{1}$ & $\pi_{11}^{1-}$ & $\ldots$ & $\pi_{11}^{f-}$ & $\pi_{12}^{1-}$ & $\ldots$ & $\pi_{12}^{f-}$ & $\ldots$ & $\pi_{1 m}^{f-}$ & $\ldots$ & $\pi_{1 m}^{f-}$ \\
$Z_{2}$ & $\pi_{21}^{1-}$ & $\ldots$ & $\pi_{21}^{f-}$ & $\pi_{12}^{1-}$ & $\ldots$ & $\pi_{12}^{f-}$ & $\ldots$ & $\pi_{1 m}^{f-}$ & $\ldots$ & $\pi_{1 m}^{f-}$ \\
$\ldots$ & $\ldots$ & $\ldots$ & $\ldots$ & $\ldots$ & $\ldots$ & $\ldots$ & $\ldots$ & $\ldots$ & $\ldots$ & $\ldots$ \\
$Z_{n}$ & $\pi_{n 1}^{1-}$ & $\ldots$ & $\pi_{n 1}^{f-}$ & $\pi_{n 2}^{1-}$ & $\ldots$ & $\pi_{n 2}^{f-}$ & $\ldots$ & $\pi_{n m}^{f-}$ & $\ldots$ & $\pi_{n m}^{f-}$ \\
\hline
\end{tabular}

Table 6: The probability weight $\pi_{i j}^{t+}(1 \leqslant i \leqslant n, 1 \leqslant j \leqslant m, 1 \leqslant t \leqslant f)$

\begin{tabular}{c|ccc|ccc|c|ccc}
\hline Criteria & \multicolumn{3}{|c|}{$C_{1}$} & \multicolumn{3}{c|}{$C_{2}$} & $\ldots$ & \multicolumn{3}{|c}{$C_{m}$} \\
\hline State & $T_{1}$ & $\ldots$ & $T_{f}$ & $T_{1}$ & $\ldots$ & $T_{f}$ & $\ldots$ & $T_{1}$ & $\ldots$ & $T_{f}$ \\
\hline Probability & $a_{1}$ & $\ldots$ & $a_{f}$ & $a_{1}$ & $\ldots$ & $a_{f}$ & $\ldots$ & $a_{1}$ & $\ldots$ & $a_{f}$ \\
\hline$Z_{1}$ & $\pi_{11}^{1+}$ & $\ldots$ & $\pi_{11}^{f+}$ & $\pi_{12}^{1+}$ & $\ldots$ & $\pi_{12}^{f+}$ & $\ldots$ & $\pi_{1 m}^{f+}$ & $\ldots$ & $\pi_{1 m}^{f+}$ \\
$Z_{2}$ & $\pi_{21}^{1+}$ & $\ldots$ & $\pi_{21}^{f+}$ & $\pi_{22}^{1+}$ & $\ldots$ & $\pi_{22}^{f+}$ & $\ldots$ & $\pi_{2 m}^{f+}$ & $\ldots$ & $\pi_{2 m}^{f+}$ \\
$\ldots$ & $\ldots$ & $\ldots$ & $\ldots$ & $\ldots$ & $\ldots$ & $\ldots$ & $\ldots$ & $\ldots$ & $\ldots$ & $\ldots$ \\
$Z_{n}$ & $\pi_{n 1}^{1+}$ & $\ldots$ & $\pi_{n 1}^{f+}$ & $\pi_{n 2}^{1+}$ & $\ldots$ & $\pi_{n 2}^{f+}$ & $\ldots$ & $\pi_{n m}^{f+}$ & $\ldots$ & $\pi_{n m}^{f+}$ \\
\hline
\end{tabular}


value $\bar{U}=\left(\bar{U}_{i j}\right)_{n \times m}$.

$$
\bar{U}=\left(\begin{array}{cccc}
\bar{U}_{11} & \bar{U}_{12} & \ldots & \bar{U}_{1 m} \\
\bar{U}_{21} & \bar{U}_{22} & \ldots & \bar{U}_{2 m} \\
\ldots & \ldots & \ldots & \ldots \\
\bar{U}_{n 1} & \bar{U}_{n 2} & \ldots & \bar{U}_{n m}
\end{array}\right)
$$

Step 4. According to the Equation (23), we construct the interval comprehensive prospect value $\bar{U}_{i}(1 \leqslant i \leqslant n)$ of each alternatives $A_{i}(1 \leqslant i \leqslant n)$.

Step 5. According to the Equation (28), we construct the priority matrix $H^{\bar{U}}=\left(h_{i k}^{\bar{U}}\right)_{n \times n}$.

$$
H^{\bar{U}}=\left(\begin{array}{cccc}
h_{11}^{\bar{U}} & h_{12}^{\bar{U}} & \ldots & h_{1 n}^{\bar{U}} \\
h_{21}^{\bar{U}} & h_{22}^{\bar{U}} & \ldots & h_{2 n}^{\bar{U}} \\
\ldots & \ldots & \ldots & \ldots \\
h_{n 1}^{\bar{U}} & h_{n 2}^{\bar{U}} & \ldots & h_{n n}^{\bar{U}}
\end{array}\right)
$$

Step 6. According to the Equation (29), we construct the Boolean matrix $Q^{\bar{U}}=\left(q_{i k}^{\bar{U}}\right)_{n \times n}$.

$$
Q^{\bar{U}}=\left(\begin{array}{cccc}
q_{11}^{\bar{U}} & q_{12}^{\bar{U}} & \ldots & q_{1 n}^{\bar{U}} \\
q_{21}^{\bar{U}} & q_{22}^{\bar{U}} & \ldots & q_{2 n}^{\bar{U}} \\
\ldots & \ldots & \ldots & \ldots \\
q_{n 1}^{\bar{U}} & q_{n 2}^{\bar{U}} & \ldots & q_{n n}^{\bar{U}}
\end{array}\right)
$$

Step 7. According to the Equation (30), we get the ranking result of the interval comprehensive prospect value $\bar{U}_{i}(1 \leqslant i \leqslant n)$ of each alternatives $A_{i}(1 \leqslant i \leqslant n)$. That is, the bigger $\lambda_{i}^{\bar{U}}(1 \leqslant i \leqslant n)$, the better $A_{i}(1 \leqslant i \leqslant n)$.

The behavior method has the following innovations.

(1) The expression way of the evaluation information and probability. We consider the hesitant fuzzy linguistic evaluation information and interval probability. This is an extension of the presentation way of evaluation information and probability.

(2) The way of comparison between the evaluation information and expectation. We propose a new and easy computed ranking method for the hesitant fuzzy linguistic term set. This is to decrease the complexity of comparison.

(3) The distance between the evaluation information and expectation. We propose a new and 
easy computed distance formula for the hesitant fuzzy linguistic term set. This is to decrease the complexity of computation.

(4) The ranking of comprehensive prospect value. We introduce a new ranking method for the interval number. This is more rational than the original possibility degree method. This is to increase the rationality of the ranking for the alternatives.

Next, we use an example to present the computed step of this method and give the relationship between the our behavior method and the existing decision making for the hesitant fuzzy linguistic term set.

\section{Numerical example}

Consider a new product development project selection problem. Let a linguistic term set $s=$ $\left\{s_{0}=\right.$ very low, $s_{1}=$ low, $s_{2}=$ a few low $s_{3}=$ medium, $s_{4}=$ a few high, $s_{5}=$ high, $s_{6}=$ very high $\}$. A certain A financial product manufacturer considers developing a new product and putting it on the market. There are five product schemes $A_{i}(1 \leqslant i \leqslant 5)$ to choose from. There are three attributes $\left(C_{1}, C_{2}, C_{3}\right)$ to consider. $C_{1}$ represents the market demand, $C_{2}$ represents the yield, and $C_{3}$ represents the payback period. Attribute $C_{1}$ and $C_{2}$ are benefit attributes, and $C_{3}$ is cost type attribute. In addition, during the product launch, there are three possible natural states $\left(S_{1}, S_{2}, S_{3}\right)$, which indicate good, medium and bad. The decision vectors and decision matrices of decision makers for each attribute are shown in Table 7.

We use our multiple attribute decision making method to get the ranking result of alternatives.

Step 1. According to the Equation (12)-(14), we construct the gained matrix $G=\left(G_{i j}^{t}\right)_{5 \times 3 \times 3}$ and losing matrix $L=\left(L_{i j}^{t}\right)_{5 \times 3 \times 3}$ (Table 8 and 9).

Step 2. According to the Equation (15)-(18), we construct the probability weight $\pi_{i j}^{t+}(1 \leqslant i \leqslant$ $5,1 \leqslant j \leqslant 3,1 \leqslant t \leqslant 3)$ of the gain $G_{i j}^{t}(1 \leqslant i \leqslant 5,1 \leqslant j \leqslant 3,1 \leqslant t \leqslant 3)$ and the probability weight $\pi_{i j}^{t-}(1 \leqslant i \leqslant 5,1 \leqslant j \leqslant 3,1 \leqslant t \leqslant 3)$ of the loss $L_{i j}^{t}(1 \leqslant i \leqslant 5,1 \leqslant j \leqslant 3,1 \leqslant t \leqslant 3)$, let $\gamma^{+}=0.61$ and $\gamma^{-}=0.69$ (Table 10 and 11$)$.

Step 3. According to the Equation (19)-(22), we construct the interval individual prospected decision making matrix $\bar{U}=\left(\bar{U}_{i j}\right)_{5 \times 3}$, let $\alpha=\beta=0.88$ and $\lambda=2.25$. 


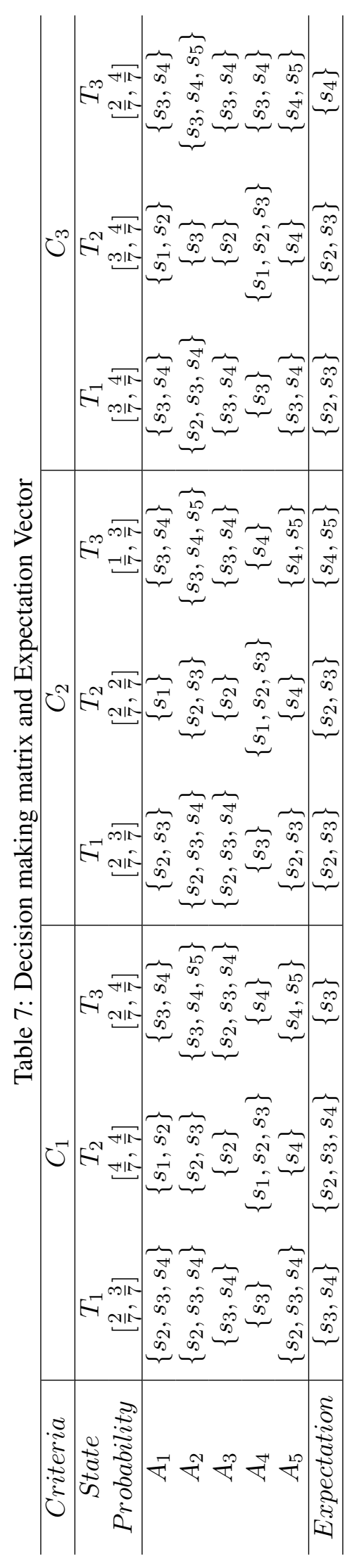




$$
U=\left(\begin{array}{ccc}
{[-0.0914,-0.0857]} & {[-0.1043,-0.0757]} & {[-0.0371,-0.0193]} \\
{[-0.0178,0.0007]} & {[-0.0021,0.0057]} & {[0.0400,0.0528]} \\
{[-0.0600,-0.0600]} & {[-0.0543,-0.0321]} & {[-0.0336,-0.0171]} \\
{[-0.0478,-0.0293]} & {[-0.0321,-0.0243]} & {[-0.0336,-0.0171]} \\
{[0.0786,0.0907]} & {[0.0271,0.0271]} & {[0.1136,0.1586]}
\end{array}\right)
$$

Step 4. According to the Equation (23), we construct the interval comprehensive prospect value $\bar{U}_{i}(1 \leqslant i \leqslant 5)$ of each alternatives $A_{i}(1 \leqslant i \leqslant 5)$, let $W=\left(\frac{1}{3}, \frac{1}{3}, \frac{1}{3}\right)$.

$\bar{U}_{1}=\frac{1}{3}[-0.0914,-0.0857]+\frac{1}{3}[-0.1043,-0.0757]+\frac{1}{3}[-0.0371,-0.0193]=[-0.0776,-0.0602]$, $\bar{U}_{2}=[0.0067,0.0197], \quad \bar{U}_{3}=[-0.0493,-0.0364], \quad \bar{U}_{4}=[-0.0378,-0.0236], \bar{U}_{5}=$ $[0.0731,0.0921]$.

Step 5. According to the Equation (28), we construct the priority matrix $\bar{H}^{\bar{U}}=\left(\bar{h}_{i k}^{\bar{U}}\right)_{5 \times 5}$.

$$
\bar{H}^{\bar{U}}=\left(\begin{array}{lllll}
1.0000 & 0.9637 & 0.9743 & 0.9625 & 0.8594 \\
1.0377 & 1.0000 & 1.0110 & 0.9988 & 0.8918 \\
1.0263 & 0.8991 & 1.0000 & 0.9879 & 0.8821 \\
1.0389 & 1.0012 & 1.0122 & 1.0000 & 0.8929 \\
1.1636 & 1.1213 & 1.1337 & 1.1200 & 1.0000
\end{array}\right)
$$

Table 8: The gained matrix $G=\left(G_{i j}^{t}\right)_{5 \times 3 \times 3}$

\begin{tabular}{c|ccc|ccc|ccc}
\hline Criteria & \multicolumn{3}{|c|}{$C_{1}$} & \multicolumn{3}{c|}{$C_{2}$} & \multicolumn{3}{c}{$C_{3}$} \\
\hline State & $T_{1}$ & $T_{2}$ & $T_{3}$ & $T_{1}$ & $T_{2}$ & $T_{3}$ & $T_{1}$ & $T_{2}$ & $T_{3}$ \\
\hline$A_{1}$ & - & - & $\frac{1}{14}$ & 0 & - & - & $\frac{1}{7}$ & - & - \\
$A_{2}$ & - & - & $\frac{1}{7}$ & $\frac{1}{14}$ & 0 & - & $\frac{1}{14}$ & $\frac{1}{14}$ & 0 \\
$A_{3}$ & 0 & - & 0 & $\frac{1}{14}$ & - & - & $\frac{1}{7}$ & - & - \\
$A_{4}$ & - & - & $\frac{1}{7}$ & $\frac{1}{14}$ & - & - & $\frac{1}{14}$ & - & - \\
$A_{5}$ & - & $\frac{1}{7}$ & $\frac{3}{14}$ & 0 & $\frac{1}{7}$ & 0 & $\frac{1}{7}$ & $\frac{3}{14}$ & $\frac{1}{14}$ \\
\hline
\end{tabular}

Table 9: The losing matrix $L=\left(L_{i j}^{t}\right)_{5 \times 3 \times 3}$

\begin{tabular}{c|ccc|ccc|cccc}
\hline Criteria & \multicolumn{5}{|c|}{$C_{1}$} & \multicolumn{3}{c|}{$C_{2}$} & \multicolumn{3}{c}{$C_{3}$} \\
\hline State & $T_{1}$ & $T_{2}$ & $T_{3}$ & $T_{1}$ & $T_{2}$ & $T_{3}$ & $T_{1}$ & $T_{2}$ & $T_{3}$ \\
\hline$A_{1}$ & $-\frac{1}{14}$ & $-\frac{3}{14}$ & - & - & $-\frac{2}{7}$ & $-\frac{1}{7}$ & - & $-\frac{1}{7}$ & $-\frac{1}{14}$ \\
$A_{2}$ & $-\frac{1}{14}$ & $-\frac{1}{14}$ & - & - & - & $-\frac{1}{14}$ & - & - & - \\
$A_{3}$ & - & $-\frac{1}{7}$ & - & - & $-\frac{1}{7}$ & $-\frac{1}{7}$ & - & $-\frac{1}{14}$ & $-\frac{1}{14}$ \\
$A_{4}$ & $-\frac{1}{14}$ & $-\frac{1}{7}$ & - & - & $-\frac{1}{7}$ & $-\frac{1}{14}$ & - & $-\frac{1}{14}$ & $-\frac{1}{14}$ \\
$A_{5}$ & $-\frac{1}{14}$ & - & - & - & - & - & - & - & - \\
\hline
\end{tabular}




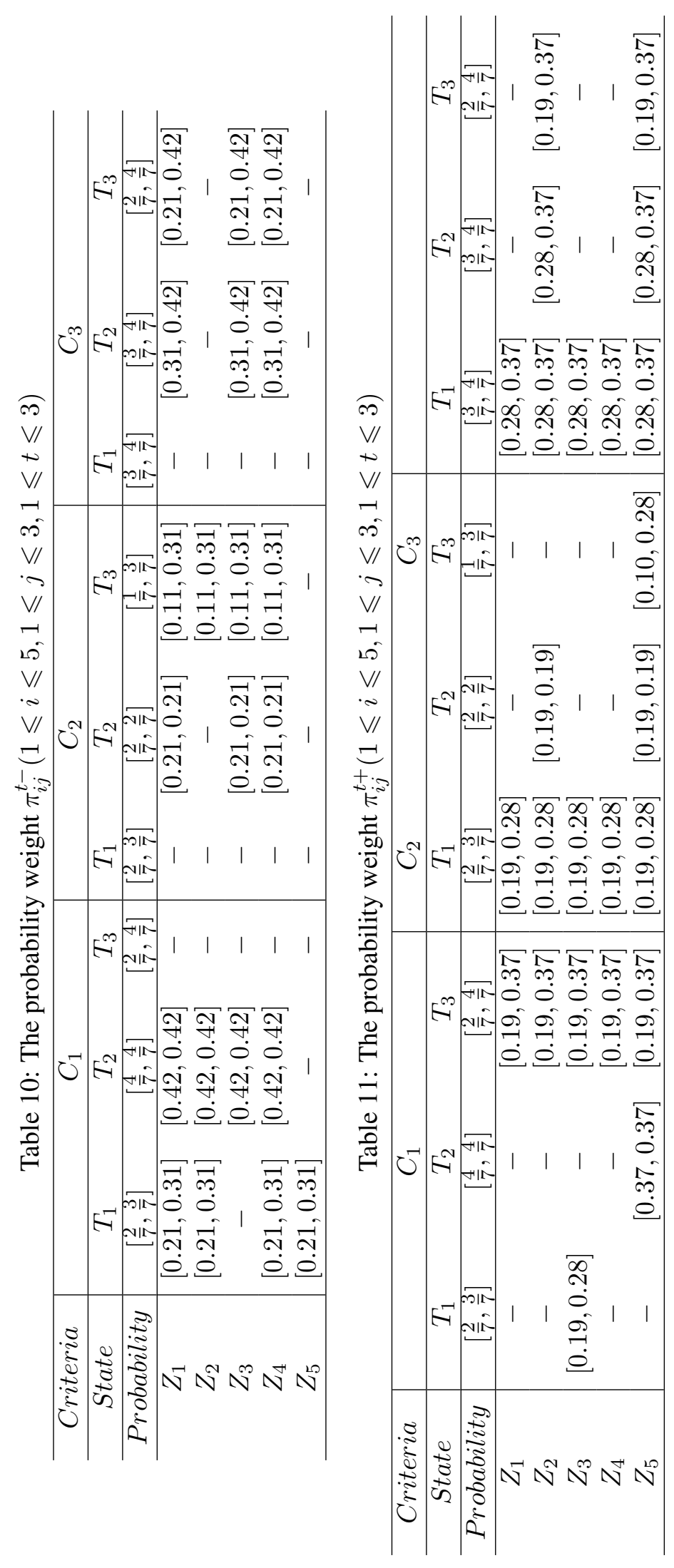


Step 6. According to the Equation (29), we construct the Boolean matrix $Q^{\bar{U}}=\left(q_{i k}^{\bar{U}}\right)_{5 \times 5}$.

$$
Q^{\bar{U}}=\left(\begin{array}{lllll}
1 & 0 & 0 & 0 & 0 \\
1 & 1 & 1 & 0 & 0 \\
1 & 0 & 1 & 0 & 0 \\
1 & 1 & 1 & 1 & 0 \\
1 & 1 & 1 & 1 & 1
\end{array}\right)
$$

Step 7. According to the Equation (30), we get the ranking result of each alternatives $A_{i}(1 \leqslant$ $i \leqslant 5) . \lambda_{1}^{\bar{U}}=1, \lambda_{2}^{\bar{U}}=4, \lambda_{3}^{\bar{U}}=2, \lambda_{4}^{\bar{U}}=3, \lambda_{5}^{\bar{U}}=5$, and $A_{1}<A_{3}<A_{4}<A_{2}<A_{5}$. So $A_{5}$ is the better choice. Obviously, this ranking result for alternatives $A_{i}(1 \leqslant i \leqslant 5)$ is rational.

\subsection{Comparative analysis}

In this section, we give the relationship between our method and the existing decision making method $^{14-23,26-35,37-43}$

- The comparison of the decision making method. These existing decision making methods 14-23, 26-35, 37-43 do not both consider the complexity of decision making information and the people's psychological state in the process of decision making. For example, the References 14-22 only considers the complexity of decision information, i.e. the expression way of decision making information are the hesitant fuzzy linguistic term sets. The References ${ }^{26-35,37-43}$ only considers the people's psychological state in the process of decision making, i.e. the prospect theory is applied to the process of decision making. However, our method both consider the the complexity of decision making information and the people's psychological state in the process of decision making.

- The comparison of the decision making environment. Here, we give the relationship between the existing decision making method and our decision making method. First, we transform the Table 7 into the Table 12-14.

The detailed steps of decision-making method for Reference ${ }^{18}$ are as follows:

1. According to the Equation (6) of Reference ${ }^{18}$, we get the 1-cuts of the hesitant fuzzy linguistic term sets, where $s(0)=\left[s_{0}, s_{6}\right], y_{11}^{1}=\left[s_{2}, s_{4}\right], y_{12}^{1}=\left[s_{2}, s_{3}\right], y_{13}^{1}=\left[s_{3}, s_{4}\right]$, 
Table 12: Decision making matrix in $S_{1}$

\begin{tabular}{c|ccc}
\hline & $C_{1}$ & $C_{2}$ & $C_{3}$ \\
\hline$A_{1}$ & $\left\{s_{2}, s_{3}, s_{4}\right\}$ & $\left\{s_{2}, s_{3}\right\}$ & $\left\{s_{3}, s_{4}\right\}$ \\
$A_{2}$ & $\left\{s_{2}, s_{3}, s_{4}\right\}$ & $\left\{s_{2}, s_{3}, s_{4}\right\}$ & $\left\{s_{2}, s_{3}, s_{4}\right\}$ \\
$A_{3}$ & $\left\{s_{3}, s_{4}\right\}$ & $\left\{s_{2}, s_{3}, s_{4}\right\}$ & $\left\{s_{3}, s_{4}\right\}$ \\
$A_{4}$ & $\left\{s_{3}\right\}$ & $\left\{s_{3}\right\}$ & $\left\{s_{3}\right\}$ \\
$A_{5}$ & $\left\{s_{2}, s_{3}, s_{4}\right\}$ & $\left\{s_{2}, s_{3}\right\}$ & $\left\{s_{3}, s_{4}\right\}$ \\
\hline
\end{tabular}

Table 13: Decision making matrix in $S_{2}$

\begin{tabular}{c|ccc}
\hline & $C_{1}$ & $C_{2}$ & $C_{3}$ \\
\hline$A_{1}$ & $\left\{s_{1}, s_{2}\right\}$ & $\left\{s_{1}\right\}$ & $\left\{s_{1}, s_{2}\right\}$ \\
$A_{2}$ & $\left\{s_{2}, s_{3}\right\}$ & $\left\{s_{2}, s_{3}\right\}$ & $\left\{s_{3}\right\}$ \\
$A_{3}$ & $\left\{s_{2}\right\}$ & $\left\{s_{2}\right\}$ & $\left\{s_{2}\right\}$ \\
$A_{4}$ & $\left\{s_{1}, s_{2}, s_{3}\right\}$ & $\left\{s_{1}, s_{2}, s_{3}\right\}$ & $\left\{s_{1}, s_{2}, s_{3}\right\}$ \\
$A_{5}$ & $\left\{s_{4}\right\}$ & $\left\{s_{4}\right\}$ & $\left\{s_{4}\right\}$ \\
\hline
\end{tabular}

Table 14: Decision making matrix in $S_{3}$

\begin{tabular}{c|ccc}
\hline & $C_{1}$ & $C_{2}$ & $C_{3}$ \\
\hline$A_{1}$ & $\left\{s_{3}, s_{4}\right\}$ & $\left\{s_{3}, s_{4}\right\}$ & $\left\{s_{3}, s_{4}\right\}$ \\
$A_{2}$ & $\left\{s_{3}, s_{4}, s_{5}\right\}$ & $\left\{s_{3}, s_{4}, s_{5}\right\}$ & $\left\{s_{3}, s_{4}, s_{5}\right\}$ \\
$A_{3}$ & $\left\{s_{2}, s_{3}, s_{4}\right\}$ & $\left\{s_{3}, s_{4}\right\}$ & $\left\{s_{3}, s_{4}\right\}$ \\
$A_{4}$ & $\left\{s_{4}\right\}$ & $\left\{s_{4}\right\}$ & $\left\{s_{3}, s_{4}\right\}$ \\
$A_{5}$ & $\left\{s_{4}, s_{5}\right\}$ & $\left\{s_{4}, s_{5}\right\}$ & $\left\{s_{4}, s_{5}\right\}$ \\
\hline
\end{tabular}


$y_{21}^{1}=\left[s_{2}, s_{4}\right], y_{22}^{1}=\left[s_{2}, s_{4}\right], y_{23}^{1}=\left[s_{2}, s_{4}\right], y_{31}^{1}=\left[s_{3}, s_{4}\right], y_{32}^{1}=\left[s_{2}, s_{4}\right], y_{33}^{1}=\left[s_{3}, s_{4}\right]$,

$y_{41}^{1}=\left[s_{3}, s_{3}\right], y_{42}^{1}=\left[s_{3}, s_{3}\right], y_{43}^{1}=\left[s_{3}, s_{3}\right], y_{51}^{1}=\left[s_{2}, s_{4}\right], y_{52}^{1}=\left[s_{2}, s_{3}\right], y_{53}^{1}=\left[s_{3}, s_{4}\right]$;

$y_{11}^{2}=\left[s_{1}, s_{2}\right], y_{12}^{2}=\left[s_{1}, s_{1}\right], y_{13}^{2}=\left[s_{1}, s_{2}\right], y_{21}^{2}=\left[s_{2}, s_{3}\right], y_{22}^{2}=\left[s_{2}, s_{3}\right], y_{23}^{2}=\left[s_{3}, s_{3}\right]$,

$y_{31}^{2}=\left[s_{2}, s_{2}\right], y_{32}^{2}=\left[s_{2}, s_{2}\right], y_{33}^{2}=\left[s_{2}, s_{2}\right], y_{41}^{2}=\left[s_{1}, s_{3}\right], y_{42}^{2}=\left[s_{1}, s_{3}\right], y_{43}^{1}=\left[s_{1}, s_{3}\right]$,

$y_{51}^{1}=\left[s_{4}, s_{4}\right], y_{52}^{1}=\left[s_{4}, s_{4}\right], y_{53}^{1}=\left[s_{4}, s_{4}\right] ; y_{11}^{3}=\left[s_{3}, s_{4}\right], y_{12}^{3}=\left[s_{3}, s_{4}\right], y_{13}^{3}=\left[s_{3}, s_{4}\right]$,

$y_{21}^{3}=\left[s_{3}, s_{5}\right], y_{22}^{3}=\left[s_{3}, s_{5}\right], y_{23}^{3}=\left[s_{3}, s_{5}\right], y_{31}^{3}=\left[s_{2}, s_{4}\right], y_{32}^{3}=\left[s_{3}, s_{4}\right], y_{33}^{3}=\left[s_{3}, s_{4}\right]$,

$y_{41}^{3}=\left[s_{4}, s_{4}\right], y_{42}^{3}=\left[s_{4}, s_{4}\right], y_{43}^{3}=\left[s_{3}, s_{4}\right], y_{51}^{3}=\left[s_{4}, s_{5}\right], y_{52}^{3}=\left[s_{4}, s_{5}\right], y_{53}^{3}=\left[s_{4}, s_{5}\right]$.

2. According to the Equation (13) of Reference ${ }^{18}$, we get the likelihood-based comparison relation $P^{i}(i=1,2,3)$, shown as follows:

$$
P^{1}=\left(\begin{array}{ccc}
\frac{1}{2} & \frac{3}{7} & \frac{4}{7} \\
\frac{1}{2} & \frac{1}{2} & \frac{1}{2} \\
\frac{4}{7} & \frac{1}{2} & \frac{4}{7} \\
\frac{1}{2} & \frac{1}{2} & \frac{1}{2} \\
\frac{1}{2} & \frac{3}{7} & \frac{4}{7}
\end{array}\right) P^{2}=\left(\begin{array}{ccc}
\frac{2}{7} & \frac{1}{6} & \frac{2}{7} \\
\frac{3}{7} & \frac{3}{7} & \frac{1}{2} \\
\frac{1}{3} & \frac{1}{3} & \frac{1}{3} \\
\frac{3}{8} & \frac{3}{8} & \frac{3}{8} \\
\frac{2}{3} & \frac{2}{3} & \frac{2}{3}
\end{array}\right) P^{3}=\left(\begin{array}{ccc}
\frac{4}{7} & \frac{4}{7} & \frac{4}{7} \\
\frac{5}{8} & \frac{5}{8} & \frac{5}{8} \\
\frac{4}{7} & \frac{1}{2} & \frac{4}{7} \\
\frac{2}{3} & \frac{2}{3} & \frac{4}{7} \\
\frac{5}{7} & \frac{5}{7} & \frac{5}{7}
\end{array}\right)
$$

3. According to the Equation (9) of Reference ${ }^{18}$ and $w=\left(\frac{1}{3}, \frac{1}{3}, \frac{1}{3}\right)$, we get the Table 15 .

Table 15: $R\left(A_{i}\right)(i=1,2,3,4,5)$ in $S_{t}(t=1,2,3)$

\begin{tabular}{c|ccc}
\hline & $T_{1}$ & $T_{2}$ & $T_{3}$ \\
\hline$A_{1}$ & 0.5034 & 0.2481 & 0.5714 \\
$A_{2}$ & 0.5000 & 0.4534 & 0.6250 \\
$A_{3}$ & 0.4534 & 0.3333 & 0.5488 \\
$A_{4}$ & 0.5000 & 0.3750 & 0.6375 \\
$A_{5}$ & 0.5034 & 0.6667 & 0.7143 \\
\hline
\end{tabular}

Table 16: The ranking result in the different state $S_{t}(t=1,2,3)$

\begin{tabular}{l|cccc}
\hline & $T_{1}$ & $T_{2}$ & $T_{3}$ & Rank \\
\hline Case 1 & 0 & $\frac{1}{3}$ & $\frac{2}{3}$ & $A_{1}<A_{3}<A_{4}<A_{2}<A_{5}$ \\
Case 2 & 0 & $\frac{2}{3}$ & $\frac{1}{3}$ & $A_{1}<A_{3}<A_{4}<A_{2}<A_{5}$ \\
Case 3 & $\frac{1}{3}$ & 0 & $\frac{2}{3}$ & $A_{1}<A_{3}<A_{4}<A_{2}<A_{5}$ \\
Case 4 & $\frac{1}{3}$ & $\frac{2}{3}$ & 0 & $A_{1}<A_{3}<A_{4}<A_{2}<A_{5}$ \\
Case 5 & $\frac{2}{3}$ & 0 & $\frac{1}{3}$ & $A_{3}<A_{1}<A_{2}<A_{4}<A_{5}$ \\
Case 6 & $\frac{2}{3}$ & $\frac{1}{3}$ & 0 & $A_{3}<A_{1}<A_{4}<A_{2}<A_{5}$ \\
Case 7 & 1 & 0 & 0 & $A_{3}<A_{2}=A_{4}<A_{1}=A_{5}$ \\
Case 8 & 0 & 1 & 0 & $A_{1}<A_{3}<A_{4}<A_{2}<A_{5}$ \\
Case 9 & 0 & 0 & 1 & $A_{3}<A_{1}<A_{2}<A_{4}<A_{5}$ \\
\hline
\end{tabular}


According to the Table 15, we know that when the probability of each state $T_{t}$ is the different, the following ranking result is also different (as Table 16). For example,

(a) If we use the priority degree method of interval number to rank the probability of occurrence of state $T_{t}$ under attribute $C_{1}$. That is, we use the priority degree method of interval number to rank $\left[\frac{2}{7}, \frac{3}{7}\right],\left[\frac{4}{7}, \frac{4}{7}\right]$ and $\left[\frac{2}{7}, \frac{4}{7}\right]$, then we get $\left[\frac{4}{7}, \frac{4}{7}\right]>\left[\frac{2}{7}, \frac{4}{7}\right]>$ $\left[\frac{2}{7}, \frac{3}{7}\right]$, which is equal to the case 2 of Table 16 ;

(b) If we use the priority degree method of the interval number to rank the probability of occurrence of state $T_{t}$ under attribute $C_{2}$. That is, we use the priority degree method to rank $\left[\frac{2}{7}, \frac{3}{7}\right],\left[\frac{2}{7}, \frac{2}{7}\right]$ and $\left[\frac{1}{7}, \frac{3}{7}\right]$, then we get $\left[\frac{2}{7}, \frac{3}{7}\right]>\left[\frac{1}{7}, \frac{3}{7}\right]>\left[\frac{2}{7}, \frac{2}{7}\right]$, which is equal to the case 5 of Table 16 ;

(c) If we use the priority degree method to rank the probability of occurrence of state $T_{t}$ under attribute $C_{3}$. That is, we use the priority degree method of interval number to rank $\left[\frac{3}{7}, \frac{4}{7}\right],\left[\frac{3}{7}, \frac{4}{7}\right]$ and $\left[\frac{2}{7}, \frac{4}{7}\right]$, then we get $\left[\frac{3}{7}, \frac{4}{7}\right]=\left[\frac{3}{7}, \frac{4}{7}\right]<\left[\frac{2}{7}, \frac{4}{7}\right]$, which is equal to the case 9 of Table 16, et al.

The result is that the people's psychological state should be considered in the process of multi-attribute decision making.

- For the ranking result of alternatives. The proposed ranking method of References ${ }^{10,18}$ is introduced by the Equation (5). However, we show that our priority degree formula for interval number is more rational than the Equation (5) by the section 5. Therefore, our priority degree method can improve the decision making method of References ${ }^{10,18}$.

- For the decision making method. Our method is a generalization of the decision-making method of Reference ${ }^{26}$, which change the expression way of decision making information and probability, and the ranking result of alternatives.

\section{Conclusions}

In this paper, we present a method for risky hesitant fuzzy linguistic multiple attribute decision making based on prospect theory and priority degree method. This method takes into account the 
psychological and behavioral characteristics of decision makers, such as reference dependence and different risk attitudes towards gains and losses. The decision makers'expectations of attributes are taken as reference points. According to the idea of prospect theory, we establish the gain matrix and loss matrix, and calculate each alternative for each attribute and establish the prospect decision matrix. On this basis, we calculate the comprehensive prospect value of each alternative to rank the alternatives. This method has the characteristics of clear concept, simple calculation process, strong operability and practicability. It provides a new way to solve decision-making problems considering decision-makers'psychological behavior(such as venture capital decision-making, project selection and so on). It has practical application value.

For the future of the decision making method, we can use it for calibration supplier selection problem, selection of alternatives, decision-making problems in maritime transportation engineering, metro station evacuation strategy selection, evaluation of knowledge management tools, ranking of website structures, improve customer satisfaction in public transportation, economic management, medical incident and business management ${ }^{36-43}$, et al, which is our future job.

\section{Declaration of interest statement}

We declare that we have no financial and personal relationships with other people or organizations that can inappropriately influence our work, there is no professional or other personal interest of any nature or kind in any product, service and/or company.

\section{References}

1. L. Zadeh. The concept of a linguistic variable and its application to approximate reasoning-i. Information Sciences, 8:199-249, 1975.

2. F. Herrera and L. Martinez. A 2-tuple fuzzy linguistic representation model for computing with words. IEEE Transaactions on Fuzzy Systems, 8:746-752, 2000.

3. I. Turksen. Type 2 representation and reasoning for cww. Fuzzy Set Systems, 127:17-36, 2002. 
4. J. Wang and J. Hao. A new version of 2-tuple fuzzy linguistic representation model for computing with words. IEEE Transaactions on Fuzzy Systems, 14:435-445, 2006.

5. I. Pérez, F. Cabrerizo, and E. Herrera-Viedma. Group decision making problems in a linguistic and dynamic context. Expert Systems with Applications, 38(3):1675-1688, 2011.

6. R. Rodríguez, L. Martinez, and F. \& Herrera. Hesitant fuzzy linguistic terms sets for decision making. IEEE Transactions on Fuzzy Systems, 14(1):109-119, 2012.

7. J. Carlos, R. Alcantuda, and V. Torra. Decomposition theorems and extension principles for hesitant fuzzy sets. Information Fusion, 41:48-56, 2019.

8. V. Torra. Hesitant fuzzy set. International Journal of Intelligent Systems, 25:529-539, 2010.

9. R. Rodíguez, Martínez L., and F. Herrera. A group decision making model dealing with comparative expressions based on hesitant fuzzy linguistic term sets. Information Sciences, 241:28-42, 2013.

10. L. Lee and S. Chen. Fuzzy decision making based on likelihood-based comparison relations of hesitant fuzzy linguistic term sets and hesitant fuzzy linguistic operators. Information Sciences, 294:513-529, 2015.

11. C. Wei, N. Zhao, and X. Tang. Operators and comparisons of hesitant fuzzy linguistic term sets. IEEE Transactions on Fuzzy Systems, 22(3):575-585, 2014.

12. C. Wei, Z. Ren, and R. Rodriguez. A hesitant fuzzy linguistic todim method based on a score function. International Joirnal of Computational Intelligence systems, 8(4):701-712, 2015.

13. G. Hesamian and M. Shams. Measuring similarity and ordering based on hesitant fuzzy linguistic term sets. Journal of Intelligent and Fuzzy Systems, 28(2):983-990, 2015.

14. H. Sellak, B. Ouhbi, and B. Frikh. A knowledge-based outranking approach for multi-criteria decision-making with hesitant fuzzy linguistic term sets. Applied Soft Computing, 67:625-640, 2018. 
15. J. Montserrat-Adell, N. Agell, and M. Sánchez. Consensus, dissension and precision in group decision by means of an algebraic extension of hesitant fuzzy linguistic term sets. Information Fusion, 42:1-11, 2018.

16. B. Farhadinia. Multiple criteria decision-making methods with completely unknown weights in hesitant fuzzy linguistic term setting. Knowledge-Base Systems, 93:135-144, 2016.

17. K. Idemitsu, H. Kozaki, and M. Yuhara. Two new approaches based on electre ii to solve the multiple criteria decision making problems with hesitant fuzzy linguistic term sets. Applied soft computing, 63:223-234, 2018.

18. L. Lee and S. Chen. Fuzzy decision making based on hesitant fuzzy linguistic term sets. Intelligent Information and Database Systems, 7802:21-30, 2013.

19. H. Xu, Z. Fan, and Y. Liu. A method for evaluating service quality with hesitant fuzzy linguistic information. International Journal of Fuzzy Systems, 20(5):1-18, 2018.

20. J. Montserrat-Adell, N. Sanchez, and M. Prats. Modeling group assessments by means of hesitant fuzzy linguistic term sets. Journal of Applied Logic, 23:40-50, 2017.

21. S. Wan, Y. Qin, and J. Dong. A hesitant fuzzy mathematical programming method for hybrid multi-criteria group decision making with hesitant fuzzy truth degrees. Knowledge-Based Systems, 138:232-248, 2017.

22. R. Liang, J. Wang, and H. Zhang. Projection-based promethee methods based on hesitant fuzzy linguistic term sets. International Journal of Fuzzy Systems, 1:1-14, 2017.

23. B. Zhang, H. Liang, and G. Zhang. Reaching a consensus with minimum adjustment in magdm with hesitant fuzzy linguistic term sets. Information Fusion, 42:12-23, 2018.

24. D. Kahneman and A. Tversky. Prospect theory: An analysis of decision under risk. Econometrica, 47(2):263-292, 1979.

25. A. Tversky and D. Kahneman. Advances in prospect theory: Cumulative representation of uncertainly. Journal of Risk and Uncertainty, 10:673-702, 1992. 
26. P. Liu, F. Jin, and X. Zhang. Research on the multi-attribute decision-making under risk with interval probability based on prospect theory and the uncertain linguistic variables. Knowledge-Based Systems, 24(4):554-561, 2011.

27. R. Krohling and T. Souza. Combining prospect theory and fuzzy numbers to multi-criteria decision making. Expert Systems with Applications, 39(13):11487-11493, 2012.

28. W. Song, Z. Chen, and X. Wang. Environmentally friendly supplier selection using prospect theory. Sustainability, 9(3):1-17, 2017.

29. W. Wang, X. Liu, and Y. Qin. A risk evaluation and prioritization method for fmea with prospect theory and choquet integral. Safety Science, 110:152-163, 2018.

30. R. Dou and G. Lin, D. aand Nan. A method for product personalized design based on prospect theory improved with interval reference. Computers \& Industrial Engineering, 125:708-719, 2018.

31. T. Ning and P. Wang. Study on disruption management strategy of job-shop scheduling problem based on prospect theory. Journal of Cleaner Production, 194:174-178, 2018.

32. H. Liu, Y. Song, and G. Yang. Cross-efficiency evaluation in data envelopment analysis based on prospect theory. European Journal of Operational Research, 273:364-375, 2019.

33. H. Xu, X. Tian, and Z. Xu. Prospect decision-making method based on hesitant fuzzy linguistic information. Chinese Journal of Management Science, 8(26):179-185, 2018.

34. S. Liu, W. Liu, and J. Qin. Three-way group decisions based on prospect theory. Journal of the Operational Research Society, 69(1):25-35, 2018.

35. Z. Wang, X. Tian, and R. Fung. An integrated decision-making approach for designing and selecting product concepts based on qfd and cumulative prospect theory. International Journal of Production Research, 56(5):2003-2018, 2018.

36. J. Qin, X. Liu, and W. Pedrycz. An extended vikor method based on prospect theory for multiple-attribute decision making under interval type-2 fuzzy environment. Knowledge-Based Systems, 86:116-130, 2015. 
37. J. Zhu, Z. Ma, and H. Wang. Risk decision-making method using interval numbers and its application based on the prospect value with multiple reference points. Information Sciences, 385-386:415-437, 2017.

38. R. Dou, D. Lin, and G. Nan. A method for product personalized design based on prospect theory improved with interval reference. Computers \& Industrial Engineering, 125(3):708-719, 2018.

39. W. Liu and L. Lei. Emergency decision-making combining cumulative prospect theory and group decision-making. Granular Computing, 4(1):39-52, 2019.

40. C. Ying, Y. Li, and K. Chin. A new product development concept selection approach based on cumulative prospect theory and hybrid-information madm. Computers \& Industrial Engineering, 122:251-261, 2018.

41. W. Dai, Q. Zhong, and C. Qi. Multi-stage multi-attribute decision-making method based on the prospect theory and triangular fuzzy multimoora. Soft Computing, 12:1-12, 2018.

42. H. Hansson and C. Lagerkvist. Decision making for animal health and welfare: integrating risk-benefit analysis with prospect theory. Risk Analysis, 34(6):1149-1159, 2014.

43. F. Ren, M. Kong, and Z. Pei. Making descriptive use of prospect theory to improve the prescriptive use of expected utility. Management Sciences, 47(11):1498-1514, 2001.

44. X. Zhang and Z. Fan. A method for risky interval multiple attribute decision making based on prospect theory. Opertions Research and Management Science, 21(3):44-50, 2012.

45. C. Kao. Interval efficiency measures in data envelopment. European Journal of Operational Research, 174:1087-1099, 2006.

46. A. Sengupta and T. Pal. On comparing interval numbers. European Journal of Operational Research, 127(1):28-43, 2000.

47. Q. Da and W. Liu. Interval number linear programming and its satisfactory solution. Systems Engineering-theory \& Practice, 19(4):3-7, 1999. 
48. Z. Xu and Q. Da. The possibility of interval number sequence method and its application. Journal of Systems Engineering, 18(1):67-70, 2003.

49. D. Li, G. Han, and W. Zeng. Ranking method of interval numbers based on boolean matrix. Control and Decision, 31(4):629-634, 2016.

50. Z. Wang, C. Shao, and L. Tang. Method for ranking interval numbers based on relative superiority and its application to multiple attribute decision making. Fuzzy Systems and Mathematics, 27(2):142-148, 2013. 